COGNITIVE MOBILITY:

LABOR MARKET RESPONSES TO SUPPLY SHOCKS IN THE SPACE OF IDEAS

\author{
George J. Borjas \\ Kirk B. Doran \\ Working Paper 18614 \\ http://www.nber.org/papers/w18614 \\ NATIONAL BUREAU OF ECONOMIC RESEARCH \\ 1050 Massachusetts Avenue \\ Cambridge, MA 02138 \\ December 2012
}

We are grateful to Patrick Ion, Graeme Fairweather, Norm Richert, and Erol Ozil from the American Mathematical Society for extensive collaboration and support in preparing the data. The authors are grateful to the Upjohn Institute, the Kauffman Foundation, and the Sloan Foundation for their financial assistance. The findings reported in this paper did not result from a for-pay consulting relationship. The views expressed herein are those of the authors and do not necessarily reflect the views of the National Bureau of Economic Research.

NBER working papers are circulated for discussion and comment purposes. They have not been peerreviewed or been subject to the review by the NBER Board of Directors that accompanies official NBER publications.

(C) 2012 by George J. Borjas and Kirk B. Doran. All rights reserved. Short sections of text, not to exceed two paragraphs, may be quoted without explicit permission provided that full credit, including $(\mathbb{C}$ notice, is given to the source. 
Cognitive Mobility: Labor Market Responses to Supply Shocks in the Space of Ideas George J. Borjas and Kirk B. Doran

NBER Working Paper No. 18614

December 2012, Revised April 2013

JEL No. J6,O31

\begin{abstract}
$\underline{\text { ABSTRACT }}$
Knowledge producers conducting research on a particular set of questions may respond to supply and demand shocks by shifting resources to a different set of questions. Cognitive mobility measures the transition from one location to another in idea space. We examine the cognitive mobility flows unleashed by the influx of Soviet mathematicians into the United States after the collapse of the Soviet Union. The data reveal that American mathematicians moved away from fields that received large numbers of Soviet émigrés. Diminishing returns in specific research areas, rather than beneficial human capital spillovers, dominated the cognitive mobility decisions of knowledge producers.
\end{abstract}

George J. Borjas

Harvard Kennedy School

79 JFK Street

Cambridge, MA 02138

and NBER

gborjas@harvard.edu

Kirk B. Doran

438 Flanner Hall

University of Notre Dame

Notre Dame, IN 46556

kdoran@nd.edu 


\title{
Cognitive Mobility: \\ Labor Market Responses to Supply Shocks in the Space of Ideas
}

\author{
George J. Borjas and Kirk B. Doran*
}

Cognitio: knowledge as a consequence of perception or of the exercise of our mental powers; a conception, notion, idea

—Charlton T. Lewis and Charles Short, A New Latin Dictionary, 1879

\section{Introduction}

Beginning with Sjaastad (1962), the study of labor mobility has been a central area of concern in labor economics. There have been countless studies of the determinants and consequences of, for example, job mobility, geographic mobility, and occupational mobility. These studies are typically motivated by the insight that mobility plays a central role in allowing labor markets to re-equilibrate in response to supply and demand shocks, improving labor market efficiency.

This paper introduces and examines the economics of a different type of mobility: cognitive mobility. We argue that in response to shocks workers not only move from one job to another, or from one geographic location to another, but also move in the more abstract space of ideas. ${ }^{1}$ Knowledge producers who are conducting research on a particular

\footnotetext{
* Harvard Kennedy School and National Bureau of Economic Research; and University of Notre Dame. We are grateful to Richard Freeman, Daniel Goroff, Daniel Hamermesh, Gordon Hanson, Bill Kerr, Solomon Polachek, Paula Stephan, Sarah Turner, two referees, and numerous seminar participants for comments on an earlier draft of this paper. We also thank Patrick Ion, Graeme Fairweather, Norm Richert, and Erol Ozil from the American Mathematical Society for extensive collaboration and support in preparing the data. We acknowledge the financial assistance provided by the Upjohn Institute, the Kauffman Foundation, and the Sloan Foundation.

1 The social sciences literature on the behavior of scientists and mathematicians contains a number of descriptive studies of cognitive mobility (see Wagner Dobler, 1999; Basu, 2011; and Basu and Wagner Dobler, 2012). These studies use migration among the fields of mathematics to determine which fields are "closer" to each other and to examine the formation of networks. In related work, Galenson (2005) and Galenson and Weinberg (2000) provide a fascinating analysis of the changing creativity of artists over the life cycle.
} 
set of questions may respond to supply and demand shocks by shifting their "mental powers" and other resources to a different set of questions. Cognitive mobility thus measures the transition from one location to another in idea space.

A number of recent studies document that the entry or exit of high-skill researchers may influence the productivity of those workers who are creatively close to them (see Azoulay, Zivin and Wang, 2010; and Waldinger, 2010) at least as much as it influences the productivity of natives who are geographically close (see Waldinger, 2012). ${ }^{2}$ This finding suggests that the costs and benefits of the immigration of knowledge producers cannot be evaluated without documenting whether natives change the type of creative work that they engage in as a response. This is a difficult question that has not yet been addressed by the literature, mainly because answering it requires determining the intellectual content of individual researchers' contributions over time.

In this paper, we examine how natives reallocate themselves in idea space as a result of a supply shock that greatly increased the number of knowledge producers working on specific topics. ${ }^{3}$ In particular, we examine the cognitive mobility of American mathematicians triggered by the influx of Soviet mathematicians after the collapse of the Soviet Union in the early 1990s. Nearly 10 percent of the Soviet mathematical workforce left the country after its political (and economic) unraveling, with a disproportionate number settling in the United States.

\footnotetext{
2 See also Furman, Kyle, Cockburn, and Henderson (2005); Hunt and Gauthier-Loiselle (2010); Kerr and Lincoln (2010); and Moser, Voena, and Waldinger (2012).

3 Cognitive mobility flows, of course, can also result from demand shocks. A simple anecdotal example will suffice: The study of the "Great Moderation" seems to have been an important topic in macroeconomics between 2000 and 2008. However, the financial crisis of 2008 and the subsequent severe recession likely motivated many of the macroeconomists studying the presumed taming of the business cycle to find more fertile (and marketable) areas of research.
} 
In Borjas and Doran (2012), we exploited the unexpected collapse of the Soviet Union and the unbalanced nature of the ensuing supply shock to show that the increased number of mathematicians in the United States led to a significant decline in the volume of scientific output produced by competing American mathematicians. ${ }^{4}$ We now examine the repercussions of the supply shock on the locational choices of American mathematicians in idea space.

Standard models of knowledge production suggest that the supply response can be either positive or negative, depending on whether spillover effects resulting from the increase in the size of the stock of ideas or the scarcity constraints implied by the law of diminishing returns dominate. As a result, the direction of flows of cognitive movers provides independent information about the relative importance of human capital spillovers in the knowledge production sector. Most important, in a world where the "true" productivity of knowledge producers is hard to measure, examining cognitive flows allows us to bypass the measurement problems. As people "vote with their minds," they share private information about relative productivities in different locations of idea space that counts of publications, patents, and citations may miss.

Our data consist of a complete tabulation of all publications by American mathematicians between 1940 and 2009, including detailed information on the "field" of each publication. ${ }^{5}$ These data allows us to examine the evolution of research topics and interests over a particular mathematician's working life. We find that the supply shock

\footnotetext{
${ }^{4}$ Abramitzky and Sin (2012) examine the codified knowledge flows (as measured by book translations) resulting from this shock. Ganguli (2013) examines how Soviet scientific research was used in the West before and after the shock.

${ }^{5}$ Dubois, Rochet, and Schlenker (2012) use a subset of this data to examine the correlates of the geographic mobility of mathematicians.
} 
generated a strong cognitive mobility response: pre-existing American mathematicians relocated within idea space to research topics and questions that did not receive a large number of Soviet émigrés. We also document that new entrants to the American mathematics community began to systematically avoid Soviet-style topics over the twodecade period after the Soviet influx.

Our analysis identifies costs that are correlated with cognitive mobility, and shows that the Soviet influx increased those costs for a significant number of American mathematicians. In particular, the data reveal that mathematicians who move to a different point in idea space take longer to produce their next paper than mathematicians who stay within their comfort zone and continue working in fields where they have prior experience. In addition to the finding that the Soviet influx increased the number of cognitive movers (and hence increased the length of the average "preparation spell" for the next paper), we also document that the length of the preparation spell itself increased significantly for those American mathematicians who experienced the stiffest competition from the Soviet émigrés. This evidence is consistent with the presence of congestion costs, as many mathematicians who work in one narrow area try to move at once to another area.

Finally, our data allows us to examine some of the determinants of cognitive mobility. In particular, we find that experienced (and likely tenured) and high-ability mathematicians were relatively less likely to switch fields than were the younger or less productive mathematicians. This implies that either the costs of cognitive mobility were higher for the best mathematicians, or that the net benefits from human capital spillovers were higher. Given that the "excess" publication lag associated with post-1992 cognitive mobility is lower for high-ability mathematicians, the evidence is most consistent with the 
conjecture that the beneficial spillover effects resulting from the influx of highly skilled Soviet mathematicians accrued mainly to the most productive American mathematicians.

\section{Conceptual Framework}

Our basic model of knowledge production is inspired by modern theories of economic growth that emphasize how human capital externalities affect the productivity of specific workers (Jones and Romer, 2012). A worker surrounded by a high-skill workforce may himself become more productive through exposure to new ideas and concepts. It is well known, however, that these spillover effects must coexist with the traditional laws of scarcity and diminishing returns that form the core of economic analysis.

Consider the simplest model where the production function for "mathematical knowledge" in the United States, $Y$, depends on the stock of ideas $I$, the stock of capital $K$ used as inputs (e.g., faculty slots and computing resources), and the stock of mathematicians $L$. Suppose there are constant returns to $K$ and $L$ and that the production function is given by:

$$
Y=I^{\phi}\left(K^{\alpha} L^{1-\alpha}\right),
$$

where $\phi$ gives the "externalities elasticity." As long as the stock of ideas is proportional to the size of the workforce, it is easy to show that the short- and long-run effects of a supply shock $(m=d \log L)$ on the marginal product of mathematicians is:

$$
d \log M P_{L}= \begin{cases}(\phi-\alpha) m, & \text { if } d \log K=0 \\ \phi m, & \text { if } d \log K=m .\end{cases}
$$


The sign of the short-run effect depends on the relative strength of the spillovers elasticity and the traditional competitive effect. Over time, however, the capital stock adjusts to the supply shock. If spillover effects exist, the long-run impact will be positive because the stock of ideas expanded, increasing worker productivity.

To introduce the notion of cognitive mobility, we allow for the possibility that the mathematics workforce is not homogenous. Mathematics, like all other disciplines, is composed of distinct "fields." The externality captured by $\phi$ is a global human capital externality: the change in the total stock of mathematical ideas shifts the productivity of all mathematicians by the same proportion. However, a supply shock that differentially affects the size of the workforce in, say, Geometric Topology and Quantum Theory might have different impacts on the stock of ideas useful to researchers in those two areas.

The simplest way to incorporate the existence of different mathematical fields is to reinterpret the variable $L$ as the number of efficiency units supplied by the mathematics workforce. ${ }^{6}$ Suppose there are $F$ distinct mathematical fields and define the total number of efficiency units as:

$$
L=\left(I_{1}^{\theta} L_{1}^{\beta}+\ldots+I_{F}^{\theta} L_{F}^{\beta}\right)^{1 / \beta},
$$

where $I_{f}$ gives the stock of ideas in field $f ; L_{f}$ gives the size of the workforce in that field; $\theta$ is the local externality elasticity measuring the size of field-specific spillovers; and the elasticity of substitution between mathematicians in different fields is $\sigma=1 /(1-\beta)$.

\footnotetext{
${ }^{6}$ See Borjas and Doran (2013b) for an extended discussion of the multi-level CES framework in the human capital externalities context.
} 
For simplicity, suppose we can categorize all research in mathematics as Sovietstyle research $(S)$ or American-style research $(A)$. Let $m_{S}$ and $m_{A}$ give the percent change in the number of Soviet-style and American-style mathematicians resulting from the supply shock following the collapse of the Soviet Union, with $m_{S}>m_{A}$. The impact of the supply shock on the relative productivity of mathematicians working in these two areas is then given by: ${ }^{7}$

$$
d \log M P_{S}-d \log M P_{A}=\left(\theta-\frac{1}{\sigma}\right)\left(m_{S}-m_{A}\right)
$$

in both the short and long runs. Note that the global externality $\phi$ does not affect the change in the relative marginal product since it expands the productivity of all mathematicians equally, regardless of field. Further, the distributional impact summarized by (4) persists in the long run, even after the capital stock has adjusted. Finally, the net impact of the supply shock can be positive or negative, depending on whether the local externality elasticity $\theta$ is larger than the competitive effect measured by the inverse of the elasticity of substitution.

Regardless of the direction of the net effect in equation (4), the supply shock may trigger a supply response. ${ }^{8}$ The sign of the net productivity impact may induce an inflow of mathematicians from other fields into the Soviet-dominated fields (if the net effect is positive), or an outflow of mathematicians currently conducting research in the Soviet-

\footnotetext{
${ }^{7}$ The derivation of equation (4) assumes that the stock of ideas in a particular field is proportional to the number of workers in that field.

${ }^{8}$ A number of related studies examine how immigration affects the human capital investment decisions of native workers. Llull (2010) estimates a structural model of the U.S. labor market, concluding that natives adjusted their human capital and labor supply behavior in response to immigration, while Hunt (2012) measures native human capital responses to immigration using a panel data set of U.S. states.
} 
dominated fields into those fields less affected by the supply shock (if the net effect is negative).$^{9}$

It is easy to describe the mechanism generating these cognitive mobility flows. Let $M P_{i S}$ and $M P_{i A}$ denote the marginal product of mathematician $\underline{i}$ in the Soviet- and Americanstyle fields, respectively. An income-maximizing mathematician who decided to conduct research in Soviet-dominated fields prior to the collapse of the Soviet Union must have satisfied the inequality $M P_{i S}>M P_{i A}$. Let $\gamma_{i}$ measure the net effect of the supply shock on the productivity of mathematician $i$. After the supply shock, a Soviet-style mathematician will engage in cognitive mobility and begin to conduct American-style research only if:

$$
M P_{i S}+\gamma_{i}<M P_{i A}-C_{i}
$$

where $C_{i}$ gives the costs of cognitive mobility (e.g., retooling skills, investing in a new network of collaborators, moving to a new institution, etc.). We assume that these mobility costs are strictly positive.

The pre-shock revealed preference of mathematician $i$ implies that a Soviet-style mathematician will switch to American-style research if and only if:

$$
\gamma_{i}<-C_{i}
$$

Since mobility costs are positive, a Soviet-style mathematician responds to the supply shock by switching to American-style research only if the net effect $\gamma_{i}$ is strongly negative. Put differently, if we were to observe many Soviet-style mathematicians switching to

\footnotetext{
${ }^{9}$ Note that the supply response in the space of ideas is not identical to a supply response in the space of occupations. A research professor may remain a research professor, at the same institution, with the same job title, institutional colleagues, pay structure, and responsibilities, while drastically refocusing his mental efforts on a different set of research questions.
} 
American-style topics in the aftermath of the supply shock, this observation necessarily implies that the adverse competitive affects arising from the supply shock must be far stronger than the positive spillovers generated by the expansion in the stock of ideas. Similarly, consider the cognitive mobility decision of mathematicians who are conducting American-style research prior to the supply shock. This subsample of mathematicians must satisfy the inequality $M P_{i A}>M P_{i S}$. Mathematicians in this group will switch to Soviet-style research after the supply shock if:

$$
M P_{i S}+\gamma_{i}-C_{i}>M P_{i A}
$$

Because these mathematicians had an initial advantage in conducting American-style research, the observation of cognitive mobility to Soviet-style fields implies that:

$$
\gamma_{i}>C_{i}
$$

In other words, cognitive mobility from American-style to Soviet-style research implies the presence of strong positive externalities.

It is important to emphasize that cognitive mobility will be observed only if the net spillover is numerically large regardless of sign. The net spillover will be strongly positive if the cognitive movers are mainly composed of mathematicians switching from American- to Soviet-style research; or it will be strongly negative if the movers flow in the opposite direction. Regardless of the sign of $\gamma_{j}$, the net spillover must outweigh the costs of cognitive mobility. We show below that these costs are sizable and likely increased after the supply shock. ${ }^{10}$

10 It is easy to expand the model to learn more about the selection that characterizes the sample of cognitive movers. After all, there is probably a great deal of heterogeneity in the magnitude of the net 


\section{Historical Context and Data}

Our empirical exploration of the concept and relevance of cognitive mobility examines the research decisions made by mathematicians in the United States prior to and after the collapse of the Soviet Union. As documented by Borjas and Doran (2012), after a long period of infrequent contacts between Soviet and Western mathematicians, over 1,000 Soviet mathematicians (or roughly 10 percent of the stock) left the Soviet Union after 1992, with around a third eventually settling in the United States. This particular historical event has a number of key features that play a crucial role in our identification strategy:

(1) The opportunity for large numbers of Soviet mathematicians to migrate to the United States arose unexpectedly and suddenly, beginning around the two-year period surrounding the collapse of Soviet communism in 1990-1991.

(2) The supply shock was large, both because of the latent demand for immigration after decades of tightly sealed borders and because of the sudden collapse of the Soviet economy (Ganguli, 2010).11

(3) Neither Soviet nor American mathematicians anticipated the abrupt opening of borders due to the lifting of the Iron Curtain, so that decisions made prior to 1992 to specialize in specific areas can be viewed as exogenous.

spillover $\left(\gamma_{i}\right)$ and migration costs $\left(C_{i}\right)$ across mathematicians. The selection rule that determines the subsample of movers will depend on the correlation between these variables and a mathematician's innate ability. We provide evidence below suggesting that high-ability mathematicians likely benefited the most from the human capital spillovers.

11 Even though the Soviet émigrés who moved to the United States increased the number of mathematicians in the country by only 1.1 percent, their pre-1992 output as defined by the number of papers published was equal to 3.4 percent of the output of American mathematicians. Grogger and Hanson (2013) document that the sample of scientific immigrants to the United States consists of persons of high academic ability. 
(4) The Soviet mathematical community was not as broad as its American counterpart; further, it excelled in specific areas due to path-dependence in Soviet mathematical insights and the relatively infrequent contact between Soviet and Western mathematicians during the decades of Soviet communist rule.

(5) The supply shock resulting from the collapse of the Soviet Union was "unbalanced" in that it increased the supply of American mathematicians working in different fields differentially; some American mathematicians were highly "exposed" to the Soviet influx, while other American mathematicians barely noticed the ripples of the shock. ${ }^{12}$

As a result, the post-1992 influx of Soviet mathematicians into the United States provides a unique opportunity to observe how native knowledge producers respond to new talent that suddenly chooses to locate close to them in the space of ideas. Around 1992, some American mathematicians faced an influx of new colleagues and competitors in their specific research areas, while other American mathematicians did not. Our empirical strategy is to compare the degree of cognitive mobility experienced by these two groups of American mathematicians both before and after the shock.

It is important to emphasize that although the field distribution of actual Soviet émigrés to the United States was selected in part due to American demand for specific types of mathematicians at that time, the historical context suggests that the distribution of all Soviet mathematicians across fields before 1992 was not related to U.S. demand. Thus, a

\footnotetext{
12 In addition to increasing the quality-adjusted number of pre-existing American mathematicians, the Soviet émigrés continued to specialize in Soviet-style fields after arriving in the United States. Soviet émigrés in the United States published 47 percent of their pre-1992 papers and 41 percent of their postmigration papers in the 1990s in Soviet-style fields (as defined below). In contrast, pre-existing American mathematicians published only 31 percent of their post-1992 papers in Soviet-style fields.
} 
key feature of the empirical strategy is its use of the potential supply shock across areas of knowledge, measured by the pre-1992 Soviet distribution of mathematicians across the fields of mathematics.

The most comprehensive data available on the published contributions of individual mathematicians (both in the United States and abroad) is contained in the American Mathematical Society's (AMS) MathSciNet archives. The AMS gave us access to the information in this archive and provided us with a database that reports the number of papers published by every mathematician in the world, by field and year, since 1939. In addition to the information on the number of papers, the AMS data reports the mathematician's institutional affiliation at the time the paper was published, as well as the location of the affiliation. The AMS, however, only began to collect the affiliation information on a systematic basis around 1984, so that affiliation and location are not typically available for earlier papers. Most important, the AMS professional staff assigns each publication in mathematics to one of the many fields that make up the study of mathematics. The AMS provided us with the author-year-field information at the two-digit field level, classifying every publication by each mathematician over the 1939-2009 period into one of 73 different fields. ${ }^{13}$

Borjas and Doran (2012) used these data, merged with information from the Thomson Reuters' Institute for Scientific Information (ISI) Web of Science archive and data from the Mathematical Genealogy Project (MGP), to construct the universe of active American mathematicians prior to the collapse of the Soviet Union. In general terms, Borjas

\footnotetext{
13 In our earlier work (Borjas and Doran, 2012), we specifically used the publication history of American mathematicians between 1978 and 1989 as the "baseline." Only 63 of the subjects are populated during that period.
} 
and Doran (2012) defined the population of active American mathematicians as composed of persons who, prior to 1989, had published predominantly using an American affiliation, or who, in the absence of any affiliation data, obtained their doctoral degree from an American institution.

The empirical analysis reported below also uses the sample of American mathematicians who first entered research activity after 1990. We apply the definitions introduced in Borjas and Doran (2012) to construct the more recent cohorts of American mathematicians. In particular, we examine the location of the affiliations reported in the papers published in the first five years of a mathematician's career, and classify the person as "American" if more than half of those publications used an American affiliation. ${ }^{14}$

We construct a panel where an observation represents a mathematician/paper permutation. For each mathematician/paper, we know both the paper's two-digit field code and the year of publication. In short, our data describes the entire publication history of American mathematicians between 1940 and 2009. Table 1 reports some summary statistics of the dataset. It contains a total of 711,497 published papers written by 78,684 unique American mathematicians, and about 44 percent of these mathematicians entered active research activity before 1992.

We wish to examine the trends in the field distribution of papers published by American mathematicians. Table 2 illustrates the dramatic differences in specializations between Soviet and American mathematics prior to the collapse of the Soviet Union. In particular, the table reports the "top ten" fields in the Soviet Union between 1984 and 1989,

\footnotetext{
14 The Data Appendix in the extended working paper version of this paper (Borjas and Doran, 2013a) contains a detailed description of the data and the construction of the samples.
} 
ranked by the share of Soviet papers in that field. The top two Soviet fields are Partial and Ordinary Differential Equations, and these two fields account for almost 18 percent of all Soviet publications. In contrast, only about 5 percent of American papers written during the period were in those two fields. More generally, the top five fields listed in Table 2 account for 35.6 percent of all Soviet publications, but only about 19.1 percent of American publications, while the top ten fields account for 53.2 percent of all Soviet publications and 36.5 percent of American publications.

To reduce the dimensionality of field choice from the 73 potential outcomes, we initially construct a simple index indicating the "Soviet-ness" of a particular mathematician's research interests at a point in time. In particular, for each paper written by an American mathematician, we create a dummy variable indicating if the paper is in a "Soviet-style field" - i.e., the paper is in one of the ten fields listed in Table 2.15 As will be shown below, we replicated our analysis using a number of alternative definitions of Soviet-style fields, as well as measures of "cognitive distance" from the Soviet research agenda, and find that the results are robust to the use of alternative classifications. Table 1 also reports summary statistics for the fraction of Soviet-style papers written by American mathematicians. The data show that the fraction of Soviet-style

\footnotetext{
15 Depending on the content of the paper, MathSciNet provides detailed information not only on the primary field classification, but also on secondary, tertiary (and even lower-level) field classifications. Although the database that AMS provided to us only contains the primary field category, we are able to determine the secondary, tertiary, quaternary, and quintinary fields (if they exist in the first place) for a nonrandom sample of 50 percent of the pre-1992 papers in the AMS database. We find that a third of the Sovietstyle papers report a sub-primary field that is not Soviet-style. But many of these fields are far down in the list: only one out of every four Soviet-style papers reports a secondary field that is not a Soviet-style field. If we assume that a paper's "true" field is a weighted average of the multiple field classifications, with the primary field weighted twice as much as the secondary field, which is weighted twice as much as the tertiary field, etc., then the average paper in our Soviet-style category has a "true" field index that is 89.2 percent Soviet-style, and the average paper in the American-style category has a "true" field index that is 1.6 percent Soviet-style. Even with variations in our weighting scheme, it is clear that our simple classification captures the predominant field content of these papers.
} 
papers written by the pre-existing group of American mathematicians declined from 33.4 percent for papers published before 1992 to 31.6 percent for papers published after 1992 . New entrants into the mathematics market also became less likely to write papers in Soviet-style fields. In particular, the table reports the probability that the first paper published by a mathematician in his career, which we will call the "dissertation" paper, is in a Soviet-style topic. The trends are revealing: 32.0 percent of dissertations written prior to 1992 were in Soviet-style topics, as compared to only 25.1 percent of dissertations written after 1992.

\section{The Determinants of Cognitive Mobility}

Suppose that each of the distinct fields of mathematics (e.g., Statistics or Numerical Analysis) represents a specific location in the space of ideas. While writing a paper in one of these fields, a mathematician resides in that location in idea space. After the mathematician completes a particular paper, he begins a "preparation spell" that ends when the subsequent paper is published.

During the preparation spell, a mathematician considers the benefits and costs of staying in the particular research area. This calculation may motivate the mathematician to remain in the same location in idea space, or to choose a new location. A supply shock of new mathematicians into a subset of locations in idea space alters the cost-benefit calculus. Citation rates in mathematics are far higher within each field than across fields. ${ }^{16}$ As a result, the increase in the stock of knowledge at a particular location in idea space resulting

\footnotetext{
16 For example, 80 percent of the citations in the papers published in the top 10 Soviet-style fields are to papers in those same 10 fields; see also Borjas and Doran (2012), p. 1169.
} 
from the supply shock could increase productivity for mathematicians already residing in that location. But the supply shock may also increase the costs of staying in that location: more mathematicians now compete for resources and attention in that field. Equally important, the mathematician recognizes that cognitive mobility is costly: the duration of the preparation spell may be longer if he must learn a new set of skills and mathematical techniques when moving to a different point in idea space.

This section examines two related questions. First, which factors induce a mathematician to move to a different location in idea space in response to a supply shock? Second, does the cognitive mobility represent a movement towards the research questions favored by newcomers or away from them? As the model presented in Section II showed, the net change in the relative marginal product that a mathematician faces in two potential locations in idea space depends on the relative strengths of (local) human capital spillovers and the increased competition implied by the law of diminishing returns. The direction of cognitive mobility flows provides information about which of these two effects is dominant.

We begin to address these questions by examining the locational choices in idea space for the group of American mathematicians who entered active research activity prior to 1992. We define two distinct groups of pre-existing American mathematicians: those whose pre-1992 dissertation was on a Soviet-style topic, and those whose pre-1992 dissertation was not. ${ }^{17}$ This simple approach exploits the fact that the pre-existing

\footnotetext{
17 Throughout the analysis, we use the term "dissertation" to refer to the first paper published in a mathematician's career. Although this is a convenient expositional device, we suspect that in most cases the subject of a mathematician's first paper is indeed the subject of the actual doctoral dissertation. We use the dissertation paper to define the groups of Soviet- and American-style mathematicians for two distinct reasons. First, the dissertation topic reflects the training acquired over a multi-year period that presumably prepared the mathematician for the research concerns he intended to pursue after the doctorate. More importantly, we define the extent of cognitive mobility by observing the field of each paper (after the dissertation paper) published over the mathematician's career. In order to avoid selecting on the dependent variable, we must
} 
mathematicians chose their dissertation topics without considering any potential costs or benefits arising from future competition or collaboration with Soviet mathematicians.

The challenge in empirically measuring cognitive mobility is that mathematicians sometimes alternate the topics that they work on from paper to paper. We need a measure of cognitive mobility that does not interpret a regular vacillation between Field \#7 and Field \#32 on a set of consecutive papers as a set of fast-paced creative journeys between these subjects; it is more likely that this vacillation itself represents the mathematician's constant "location" in the space of ideas.

We initially consider two conceptually distinct ways to measure a change in location in the space of ideas. First, we can observe whether each of the mathematician's future papers is in the same area as the dissertation topic, and measure how the probability of writing in one's dissertation area changes over time-and particularly how it changes after the Soviet supply shock. This approach is akin to thinking of a mathematician's "location" in the space of ideas as the probability distribution of that mathematician's output across fields. For simplicity, we reduce the dimensionality of the measurement by dividing fields into two categories (Soviet- and American-style). We further simplify the measurement problem by measuring all changes relative to the field of the dissertation paper.

Alternatively, we can define cognitive mobility by observing the first time that a mathematician publishes in a specific field. We can measure the probability that mathematicians write for the first time in a new area where they have never worked in before, and again observe how this probability evolves over time. This measure of cognitive

exclude from our regressions any papers used to define our subgroups. The definition of the subgroups according to the field of the first published paper allows our regressions to exclude as few papers as possible. Our results are robust to using additional papers (e.g., papers published in the first 2 or 5 years) to define the subgroups of mathematicians. 
mobility is obviously not identical to the measure defined in the previous paragraph; even if the distribution of papers across subjects does not change appreciably, the tendency to explore a brand-new area may (or may not) change a great deal over time.

As noted above, we reduce the dimensionality of locations in idea space by compressing the 73 fields of mathematics into two categories: (1) Soviet-style fields, composed of the 10 fields that were the most populated in the Soviet Union prior to the collapse; and (2) American-style fields, the residual group of the 63 other fields. ${ }^{18}$

Using this simple two-way classification, we plot our first measure of cognitive mobility, the probability that a paper written in year $t$ is in a different field than the dissertation, in the top panel of Figure 1. In the 1980s, before the collapse of the Soviet Union, American mathematicians who wrote their dissertations on American-style topics had an average probability of about 20 percent of writing in a Soviet-style field in later papers. This probability remained roughly constant after the Soviet influx; in fact, if anything, there is a slight decline after 1992. The evidence thus suggests that the supply shock either had no impact or a small negative impact on the propensity for cognitive mobility among mathematicians who began their career in American-style fields. In terms of the model, it seems that the mobility costs of locating in a different point in idea space for American-style mathematicians far exceed any (potential) positive spillover effects.

In contrast, before the collapse of the Soviet Union, American mathematicians who wrote their dissertations on Soviet-style topics had a 30 to 35 percent probability of writing on a non-Soviet topic in each of their later papers. But this probability began to

\footnotetext{
18 This reduction in dimensionality implies that the "brand new field" measure of cognitive mobility identifies the first time that a mathematician with a Soviet-style (American-style) dissertation switched to American-style (Soviet-style) research.
} 
increase rapidly after the Soviet influx, reaching a peak of about 50 percent by 2005 . The data thus suggests that the supply shock substantially increased the propensity for cognitive mobility among American mathematicians who wrote a Soviet-style dissertation. Put differently, the data reveal that American mathematicians who started their careers in a location in idea space that received a large number of Soviet émigrés responded to the influx by moving to a new location that received fewer immigrants. In terms of the model, the direction of the flow of cognitive movers implies that the net spillover effect must be strongly negative since it must outweigh the mobility costs.

Panel B of Figure 1 illustrates the trends using our second measure of cognitive mobility, a measure that indicates whether a mathematician entered a "brand new" field in year $t$ (i.e., a field where he had never published before). The figure clearly shows that, within a few years after the start of the Soviet influx, there was a sharp increase in the tendency of Soviet-style mathematicians to explore other (i.e., non-Soviet) research areas for the first time. Note that the increase in the rate of cognitive mobility is observed around five years after the supply shock. As we will show in the next section, this timing roughly coincides with the amount of time required to retool mathematical skills from Americanstyle to Soviet-style fields. In short, both panels of Figure 1 demonstrate a large increase in the rate of cognitive mobility, however it is measured, for Soviet-style mathematicians after the influx of Soviet émigrés.

To examine the sensitivity of our findings to controlling for various background characteristics, we estimated the linear probability regression model:

$$
p_{\text {in }}(t)=\delta_{i}+\delta_{t}+\theta\left(T_{i} \times S_{i}\right)+Z_{i} \beta+\varepsilon,
$$


where $p_{i n}(t)$ is the probability of cognitive mobility from the dissertation to paper $n$ published by mathematician $i$ in calendar year $t$; $T$ is a dummy variable indicating if that paper was published after 1992; $S_{i}$ is a dummy variable indicating if the mathematician's dissertation topic was in a Soviet-style field; $Z$ is a set of characteristics that may influence a mathematician's location in idea space (discussed below); and $\delta_{i}$ and $\delta_{t}$ are vectors of individual and calendar year fixed effects, respectively. It is important to emphasize that this regression model is estimated using only the sample of pre-existing American mathematicians. ${ }^{19}$

Table 3 reports the relevant coefficients from this regression model using several alternative specifications. Regardless of the specification, we find that the supply shock led to a substantial increase in cognitive mobility out of Soviet-style areas and into Americanstyle work. Consider, for instance, the simplest specification reported in column 1, which only includes a mathematician's years of experience (introduced as a quartic) in the vector $Z$. The coefficient of the interaction variable between the post-1992 indicator and the variable indicating whether the mathematician wrote a Soviet-style dissertation is around .12, regardless of the measure of cognitive mobility used. Put differently, the (relative) probability of moving to American-style research for Soviet-style mathematicians increased by about 12 percentage points after the supply shock..$^{20}$

\footnotetext{
19 The regressions that use the measure of cognitive mobility to a "brand new field" as a dependent variable only include those spells that potentially allow for such a move occur. Once a Soviet-style (Americanstyle) mathematician writes his first-ever American-style (Soviet-style) paper, all subsequent spells in that mathematician's career must have a zero for the dependent variable. We exclude all those subsequent spells from the regressions.

20 We briefly note two distinct robustness checks. First, although the standard errors reported in the tables adjust for individual-level heteroscedasticity, the results remain statistically significant if we cluster the standard errors at the broader dissertation-field level. Second, four subjects were added during the revision of the Mathematics Subject Classification in 2000. Our results, however, are not affected by this
} 
The data also allows us to examine the question of which mathematicians are most likely to engage in cognitive mobility. As our model showed, cognitive mobility occurs when the net spillovers due to an influx of mathematicians into a particular location in idea space outweigh the costs of migration. As a result, the cognitive movers are a self-selected group of mathematicians. Hence, we can examine the distinctive characteristics of this group to learn about how the net spillovers or the mobility costs differ among different mathematicians.

The second column of the table includes two additional variables in the vector $Z$ : an indicator of whether the mathematician was likely to be tenured as of 1992, and the mathematician's rate of output, as measured by the number of papers that the mathematician published annually prior to $1992 .{ }^{21}$ The individual fixed effects, of course, subsume the direct effect of both of these variables. Nevertheless, it is possible that their impact differs in the pre- and post-shock periods. Column 2 reports the interaction of these "quality" variables with the post-1992 indicator. It is noteworthy that both of these interaction variables are negative (in Panel A), although only the pre-1992 rate of output is statistically significant.

A more interesting specification allows for the impact of these "quality" variables to differ not only pre- and post-shock, but also between American- and Soviet-style

reclassification and are robust when papers published in the newly defined subjects are removed from the sample.

21 We do not observe directly if a mathematician was tenured at the time of the collapse of the Soviet Union. The "tenured as of 1992" variable is a dummy variable indicating if the mathematician had at least 10 years of experience as of 1992 (i.e., his first publication occurred prior to 1982). At the time, post-doctoral fellowships in mathematics were relatively rare, so that a mathematician who continued to publish in academic journals after his first decade in the profession likely had attained tenure at an academic institution. 
mathematicians. The fully interacted model presented in the third column of Table 3 reports the coefficients from this expanded specification.

Consider the variable measuring whether the mathematician was tenured at the time of the supply shock in the regression that examines cognitive mobility to a "brand new" field. The three-way interaction (post-1992 indicator $\times$ Soviet-style dissertation $\times$ tenured as of 1992) is strongly negative, indicating that the impact of the supply shock in driving Soviet-style mathematicians away from Soviet-style research was attenuated if the mathematician had job security at the time..$^{22}$ Note that the numerical magnitude of this attenuation effect is large: the probability of moving for the first time to an American-style research area after the Soviet supply shock falls by 3.5 percentage points if the mathematician was tenured.

Similarly, although the inclusion of individual fixed effects controls for differences in individual quality, there may be a differential effect between high- and low-ability mathematicians. The last column of Table 3 shows that the coefficient of the three-way interaction variable (post-1992 indicator $\times$ Soviet-style dissertation $\times$ rate of output) is also negative and significant, suggesting that high-ability Soviet-style mathematicians were relatively less likely to move after the supply shock.

The numerical magnitude of the coefficient is interesting. In particular, the impact of the supply shock on cognitive mobility approaches zero when the rate of output has a value of between 3.5 and 12.7, depending on the definition of cognitive mobility. ${ }^{23}$ This threshold

\footnotetext{
22 Note, however, that the effect of the "tenure" variable is only statistically significant in the regression that uses the 'brand new field' measure of cognitive mobility.

23 For example, the coefficient of the two-way interaction between the post-1992 indicator and the Soviet-style dissertation in Panel B is .216, while the coefficient of the three-way interaction between these two variables and the rate of output is -.062 . The net effect is zero when the rate of output is 3.5 . The rate of
} 
roughly marks the $95^{\text {th }}$ percentile of the rate of output distribution across mathematicians, so that the most prolific Soviet-style mathematicians chose to stay in those locations in idea space where the Soviet émigrés clustered. In short, the probability of cognitive mobility rose markedly for the "average" Soviet-style mathematician, but did not change (or perhaps fell) for high-ability Soviet-style mathematicians.

In sum, the data reveal the presence of a potentially important type of selection: the cognitive mobility effects of the supply shock are attenuated for the best American mathematicians who did Soviet-style research. This type of selection can only occur if either the net human capital spillovers are positive and very large for the most productive Soviet-style mathematicians or if their mobility costs are relatively high. We will address these alternative hypotheses in more detail in the next section. ${ }^{24}$

It is worth noting that the effects documented in Table 3 are robust to the use of alternative definitions of "Soviet-style" fields. In particular, Table 4 re-estimates the basic set of regressions using a number of alternative definitions. For expositional convenience, the top row of the table summarizes the main set of coefficients resulting from the simplest definition (the 10 fields with the largest shares of papers in the Soviet Union before 1989), using the fully interacted specification.

output variable takes on a value of 3.6 at the $90^{\text {th }}$ percentile, 4.7 at the $95^{\text {th }}$ percentile, and 7.5 at the $99^{\text {th }}$ percentile.

24 In the appendix of Borjas and Doran (2013a), we extend the empirical analysis to examine the evolution of a mathematician's research interests over the life cycle, and how the life cycle path of research interests was disrupted by the supply shock initiated by the collapse of the Soviet Union in 1992. We find that the supply shock reduced the degree of creative diversity over the life cycle for American-style mathematicians because it reduced their incentives to engage in Soviet-style topics, but increased the degree of creative diversity for Soviet-style mathematicians by encouraging their move to American-style work. 
To illustrate the construction of the alternative definitions, let $\Delta=s_{f}-a_{f}$, where $s_{f}$ is the share of pre-1989 papers published in field $f$ in the Soviet Union, and $a_{f}$ is the share of papers published in that field in the United States. Row 2 of the table reports the regression results when the Soviet-style fields are defined as the ten fields with the largest values of the differenced share $\Delta$. There is, of course, a significant overlap between this definition of Soviet-style fields and the simpler one used in row 1 , but this alternative definition allows for the fact that even though a field like Operations Research, Mathematical Programming was popular in the Soviet Union, it was even more popular in the United States. Despite the difference in the definition of Soviet-style fields, the regression coefficients are barely affected.

Row 3 defines the group of Soviet-style fields by using the top 10 fields in the relative share given by $R=s_{f} / a_{f}$ This definition is obviously susceptible to the presence of "outlier" fields. ${ }^{25}$ Nevertheless, the regression coefficients yield qualitatively similar results (although with larger standard errors). Finally, to prevent the classification of Soviet-style fields from being dominated by fields that attract a very small number of American mathematicians (and hence lead to a very high value of $R$ ), row 4 of the table redefines the Soviet-style fields as the 10 fields that have the largest values of the relative share $R$ as long as the field had a significant pre-1989 American presence (in particular, $a_{f}$ is above the

\footnotetext{
25 For example, Integral Equations accounted for 1.3 percent of Soviet publications, but only for 0.3 percent of American publications, and has the largest value of the relative share (4.1)
} 
median). ${ }^{26}$ The comparison of rows 1 and 4 of the table again shows that the regression coefficients are quantitatively very similar. ${ }^{27}$

We also constructed two distance-based measures of cognitive mobility. The first uses the similarity index between the research interests of a particular American mathematician and the pre-1990 Soviet field distribution. Let $a_{i f}$ be the share of papers that American mathematician $i$ published in field $f$, and let $s_{f}$ be the share of all Soviet papers published in field $f$ before the collapse of the Soviet Union. The index of similarity (Cutler and Glaeser, 1997) for mathematician $i$ is defined by:

$$
D_{i}=1-\frac{1}{2} \sum_{f}\left|a_{i f}-s_{f}\right|
$$

We calculate the value of the similarity index for every paper written by an American mathematician. It is easy to show that the value of the index of similarity for paper $n$ written by mathematician $i$ in field $f$ at time $t$ collapses to:

$$
D_{i f n}(t)=s_{f}
$$

In other words, the index of similarity for a particular paper is simply the value of the Soviet share of the field associated with that paper.

We can use the progression of the index of similarity across papers over the life cycle to measure the cognitive distance traveled (in terms of the "Soviet-ness" of the research topic) between the dissertation paper and paper $n$, and to determine if this publications.

${ }^{26}$ The 31 fields above the median of $a_{f}$ accounted for 86.7 percent of all pre-1989 American

27 The results are unlikely to be an artifact of differential trends in the funding of fields in mathematics. After all, mathematicians rarely rely on grants to produce their theorems. Further, Borjas and Doran (2012, Table III, Panel D) show that the competitive forces (which provide the incentive for cognitive mobility in the most affected fields) were robust to the inclusion of a full set of field-year fixed effects. 
distance was affected by the Soviet supply shock. In particular, let $\Delta_{i n}(t)=D_{i f n}(t)-D_{i f 1}\left(t^{\prime}\right)$, which is simply the difference in the share $s_{f}$ between the $n^{\text {th }}$ and the first paper in a mathematician's career. We estimated the generic regression model in equation (9) by using both $\Delta_{i n}(t)$ and its absolute value $\left|\Delta_{i n}(t)\right|$ as dependent variables, and using the interaction between the post-1992 indicator and the similarity index of the dissertation paper as the key independent variable. The absolute value specification, of course, measures the presence of any type of mobility (akin to using a dummy variable indicating a cognitive move), while the sign of $\Delta_{\text {in }}$ reflects the direction of the flow of cognitive movers. The top panel of Figure 3 illustrates the trend in the absolute value measure of cognitive distance. It shows an increase in "distance traveled" after 1992 for mathematicians who wrote a Soviet-style dissertation. The basic regression specifications yield: ${ }^{28}$

$$
\begin{gathered}
\left|\Delta_{\text {in }}(t)\right|=\delta_{i}+\delta_{t}+.097\left(T_{i} \times D_{i f 1}\right) \\
(.008) \\
\Delta_{\text {in }}(t)=\delta_{i}+\delta_{t}-.098\left(T_{i} \times D_{i f 1}\right)
\end{gathered}
$$

The positive interaction in equation (12) shows that the cognitive distance traveled between the dissertation and the $n^{\text {th }}$ paper (in terms of the paper's Soviet share) increases after 1992 for mathematicians who wrote a more Soviet-like dissertation, even after controlling for individual and period fixed effects. Put differently, Soviet-style mathematicians moved to a more distant location in idea space after 1992 . The negative interaction in equation (13) reveals the direction of that move: American mathematicians

28 The regressions reported in equations (12) and (13) include a quartic in years of experience, and the standard errors are clustered at the individual level. 
who wrote a Soviet-style dissertation chose research topics after 1992 that were less congruent with the Soviet research program..$^{29}$

The second measure of cognitive distance uses the frequency with which fields cite each other to create a metric across the 73 fields of mathematics. Specifically, let $c_{f g}$ be the share of citations made by papers published in field $f$ to papers published in field $g \cdot{ }^{30}$ The cognitive distance traveled by a mathematician when he moves from publishing a paper in field $f$ to a paper in field $g$ can then be defined as:

$$
\Omega_{f g}=\frac{\left(c_{f f}-c_{f g}\right)}{\max _{g}\left(c_{f f}-c_{f g}\right)} .
$$

By construction, the index $\Omega_{f g}$ equals zero when the mathematician "travels" from one paper in field $f$ to another paper in field $f$, and reaches the upper limit of one when he travels from a paper in field $f$ to a paper in field $g$, where $g$ is the field least cited by papers published in field $f$. Note that there is an important conceptual difference between the two cognitive distance indices given by $\Delta$ and $\Omega$. The former measures distance in terms of "Soviet-ness," while the latter measures distance in terms of intellectual content.

The median cognitive distance $\Omega$ between fields $f$ and $g$ (excluding all $f=g$ pairs) is .99. In fact, only the "closest" two percent of "field pairs" have cognitive distances of .75 or lower, implying that almost all mathematical fields are equally "intellectually far" from each other. In short, the data reveal that most fields "spend" almost all of their citations on

${ }^{29}$ We also estimated fully interacted regression specifications that included the tenured and rate of output variables. The qualitative impact of these interactions is identical to that reported in Table 4.

30 The citation share $c_{f g}$ is obtained from a 50 percent sample of the AMS database that we matched paper-by-paper with the ISI Web of Science. The ISI Web of Science includes full information on the list of publications that each paper cited in its references section. We calculate this citation share using the sample of papers published before 1992. 
papers published in a handful of very closely related fields (and especially in within-field citations).

Let $\Omega_{i n}(t)$ denote the cognitive distance between the $n^{\text {th }}$ paper published by mathematician $i$ at time $t$ and the dissertation paper. Panel B of Figure 3 illustrates the effect of the shock on this measure of cognitive distance. It is evident that there was a post1992 increase in intellectual "distance traveled" for mathematicians who wrote a Sovietstyle dissertation. The basic regression specification yields: ${ }^{31}$

$$
\Omega_{\text {in }}(t)=\delta_{i}+\delta_{t}+.043\left(T_{i} \times S_{i}\right)
$$

The positive interaction in (15) shows that the distance traveled increases significantly after 1992 for mathematicians who wrote a Soviet-like dissertation, even after controlling for individual and period fixed effects. Put differently, we again find that Soviet-style mathematicians moved to a more distant location in idea space after 1992.32

Finally, it is important to determine if the cognitive mobility away from Soviet-style research by American mathematicians was a result of an immigration-induced supply shock that specifically affected the United States or reflects a general worldwide trend resulting from an "idea shock" that affected Soviet-style mathematicians in all countries. As we noted earlier, nearly 10 percent of the active mathematics workforce in the Soviet Union emigrated after 1992. As a result of this influx, the (quality-adjusted) number of

31 The regression reported in equation (14) again includes a quartic in years of experience, and the standard errors are clustered at the individual level.

32 The results are very similar if we measure cognitive distance using an "index of dissimilarity" constructed from the citation matrix. 
mathematicians in the United States increased by 3.4 percent, while the respective increase in supply outside the United States was 2.0 percent. $^{33}$

To determine if the differential size of the supply shocks had a relatively larger effect on the cognitive mobility rate of Soviet-style mathematicians in the United States, we re-estimated the regression model in equation (9) using a pooled sample composed of American mathematicians and mathematicians in the "rest of the world." 34 We then interacted the Soviet dissertation measure with an indicator variable $U S A_{i}$ set to unity if mathematician $i$ is American. The expanded regression model is given by:

$$
p_{\text {in }}(t)=\delta_{i}+\delta_{t}+\theta\left(T_{i} \times S_{i}\right)+\theta\left(T_{i} \times S_{i} \times U S A_{i}\right)+Z_{i} \beta+\varepsilon,
$$

Table 5 presents the relevant regression coefficients using our two main measures of cognitive mobility (based on the top 10 Soviet fields). It is evident that there was a higher rate of cognitive mobility away from Soviet-style research fields in the United States than in the rest of the world. ${ }^{35}$

33 The percent increase in supply is weighted by the number of papers published by the various mathematicians between 1987 and 1991. The quality-adjusted measure of the supply shock is far greater than the percent increase in the number of active mathematicians: the émigré flow only increased the number of mathematicians by 1.1 percent in the United States and .4 percent in the rest of the world.

34 The sample of pre-existing mathematicians in the "rest of the world" consists of the residual sample of non-American and non-Soviet mathematicians. Because it is difficult to establish national origin outside the United States and the Soviet Union for older mathematicians, we restrict the regression analysis to mathematicians whose first paper was published after 1960.

35 It is easy to carry out a back-of-the-envelope calculation of the ceteris paribus impact of the supply shock (assuming that the "idea shock" affected mathematicians in all countries equally). In particular, note that there is a 1.4 percentage point difference in the supply shock between the United States and the rest of the world. The interaction coefficient reported in the first column of Table 5 suggests that this difference was responsible for a 3.1 percentage point relative increase in the cognitive mobility rate of American mathematicians. Put differently, a supply shock that increases supply by one percent increases the rate of mobility by 2.2 percentage points (or the ratio of 3.1 to 1.4 ). As a result, the 3.4 percent supply shock experienced by the United States would be predicted to increase the rate of cognitive mobility of Soviet-style American mathematicians by 7.5 percentage points. 


\section{The Costs of Cognitive Mobility}

Cognitive mobility may be costly. A mathematician may need to acquire additional technical skills to prove theorems at the new location in idea space. This process takes time and may lead to a longer "preparation spell" (i.e., the amount of time that the mathematician spends preparing and marketing a new publication). It is easy to document, in fact, that preparation spells are longer if the spell involves a switch to a new field. The Soviet supply shock could then potentially increase the costs of cognitive mobility in two distinct ways. First, it increased the propensity for cognitive mobility among Americanstyle mathematicians. Second, the clustering of large numbers of Soviet mathematicians in specific locations in idea space could increase the length of the preparation spell for cognitive movers.

Table 6 summarizes some of the available evidence on the length of preparation spells for Soviet- and American-style mathematicians, before and after the supply shock. ${ }^{36}$ We define the duration of a preparation spell as the length of time elapsed (in years) between any two consecutive papers in a mathematician's career. As Panel A shows, even before the supply shock, switching fields involved a slightly longer preparation spell. The preparation spell between two consecutive American-style papers lasted 1 year, as compared to 1.2 years for a move from American- to Soviet-style research. Similarly, the preparation spell between two consecutive Soviet-style papers was .8 years, but a move from Soviet-style to American-style research took 1.1 years.

${ }^{36}$ Since the evidence is robust to the definition of Soviet-style fields, we use the simplest definition in the remainder of the analysis (the 10 fields with the largest Soviet shares of pre-1989 papers). 
Panel B shows that one particular type of preparation spell was extremely sensitive to the Soviet supply shock, namely the one reporting the duration of the preparation spell for Soviet-style mathematicians who are writing their first-ever American-style paper. The duration of this particular type of preparation spell increased dramatically from 2.3 years in the pre-shock period to 5.1 years after the supply shock, or an increase of 2.8 years. In contrast, the supply shock increased the duration of time involved in the preparation of the first-ever Soviet-style paper by 1.2 years (from 2.2 to 3.4 years).

We examine the sensitivity of these findings to controlling for various characteristics by estimating the regression model:

$$
\begin{aligned}
y_{i n}(t)= & \delta_{i}+\delta_{t}+\theta_{0}\left(S_{i} \times F_{i n}\right)+\theta_{1}\left(T_{i} \times S_{i}\right)+\theta_{2}\left(T_{i} \times S_{i} \times F_{i n}\right) \\
& +\kappa_{0}\left(A_{i} \times F_{i n}\right)+\kappa_{1}\left(T_{i} \times A_{i}\right)+\kappa_{2}\left(T_{i} \times A_{i} \times F_{\text {in }}\right)+Z_{i} \beta+\varepsilon,
\end{aligned}
$$

where $y_{i n}(t)$ is the duration of the preparation spell that culminated in mathematician $i$ publishing paper $n$ at time $t$; $F_{\text {in }}$ is a dummy variable indicating if this particular spell ended with the mathematician publishing a paper in a "brand-new" field (i.e., a field that he had not previously explored); and $A_{i}=\left(1-S_{i}\right)$. Note that the regression includes both time and individual fixed effects. ${ }^{37}$

The data consists of a panel that includes each preparation spell experienced by every pre-existing American mathematician in our sample. Table 7 reports the relevant regression coefficients. Consider initially the simplest specification reported in column 1 , which only includes a quartic in years of experience in the vector $Z$. The coefficients of the

\footnotetext{
${ }^{37}$ It is worth noting that the inclusion of individual fixed effects implicitly controls for very fine differences in mobility rates across mathematical fields. In particular, it controls for the ease of moving out of the "dissertation" field even if the dissertation field were defined in terms of one of the 73 fields reported in the AMS data.
} 
two-way interactions between the dissertation's research style and the indicator of switching to a new field are essentially identical for American- and Soviet-style mathematicians. The three-way interaction with the post-1992 indicator, however, is much greater for American mathematicians who wrote a Soviet-style dissertation. The difference between these two coefficients, which is approximately around a year, indicates that our earlier conclusion based on the raw data is unaffected by the inclusion of individual and year fixed effects: Soviet-style mathematicians entering a new field had a substantial (relative) increase in the duration of the preparation spell after the supply shock. ${ }^{38}$

The last column of the table shows that this increase is attenuated somewhat for high-ability mathematicians. As in the last section, we introduce a variable measuring the rate of output for mathematician $i$ prior to the supply shock. The coefficients reported in the table suggest that the Soviet supply shock particularly lengthened the duration of the preparation spell for low-quality Soviet-style mathematicians moving to an entirely new location in idea space after 1992.

In sum, not only is there a strong positive correlation between the duration of the preparation spell and the propensity to enter a new field, but the correlation increased markedly after the supply shock. This observed increase is consistent with two causal scenarios: (1) the supply shock made it relatively more difficult for Soviet-style mathematicians to produce (and/or sell) output, creating a longer down time in between publications and spurring some of them to seek a new location in idea space; or (2) the supply shock induced Soviet-style mathematicians to cognitively move, and the subsequent retooling implies that it took them longer to prove their first theorems in their new location

38 The difference is statistically significant, with a $t$-statistic of 4.62 . 
in idea space. Under the first scenario, cognitive mobility does not cause time lags, but is rather caused by them. Under the second scenario, the causation is reversed. The natural experiment we exploit in this paper is not designed to distinguish these causal chains from each other. Nevertheless, the data reveal an important correlation that will likely play a role in future attempts to understand the nature of the costs of cognitive mobility.

Finally, it is worth returning to an important question regarding the selection of cognitive movers: Why did the best Soviet-style mathematicians exhibit the lowest mobility rates in response to the Soviet supply shock? As we noted earlier, this correlation can be explained in two ways: the best mathematicians benefited the most from the positive spillovers generated by the expansion in the stock of mathematical ideas and/or the best mathematicians had the highest cognitive mobility costs. The results presented in this section, however, strongly suggest that the best Soviet-style mathematicians, in fact, faced relatively lower cognitive mobility costs. As a result, the evidence implies that the beneficial human capital spillovers resulting from the Soviet supply shock most likely accrued to the subsample of the most productive American mathematicians, and that these spillovers effectively neutralized the adverse competitive effects in this productive group.

\section{Field Choices of New Cohorts}

Up to this point, we have examined the cognitive mobility response among "preexisting" American mathematicians to the economic forces unleashed by the collapse of the Soviet Union. The empirical evidence unambiguously suggests that the competitive pressures arising from a new abundance of Soviet-type mathematicians led many preexisting mathematicians to switch away from those fields. 
Obviously, the same economic forces will likely influence field choices for new entrants into the American mathematics market. ${ }^{39}$ Graduate students, as they prepare their dissertation and invest in the skills required to become specialists in their chosen fields, will inevitably consider the long-term value of the various options available, and will make a decision based not only on the suitability of the match between their specific skills and the technical requirements of particular fields, but also on the marketability of research in specific fields. The trend in the number of new mathematicians choosing to specialize in Soviet fields would then provide independent evidence on the relative importance of competitive versus spillover effects. Fewer new American mathematicians will choose to produce a Soviet-style dissertation if competitive forces dominate, while many more new mathematicians would produce Soviet-style dissertations if the productivity gains resulting from the Soviet supply shock are substantial.

We illustrate the nature of these "cohort effects" by examining the field choice of the first paper published by each mathematician. As before, we call this field choice the dissertation field. ${ }^{40}$ In order to control for the effect of worldwide fads and knowledge developments, we use a control group of mathematicians in the "rest of the world" - the mathematical community outside the United States and the (former) Soviet Union. Recall that the Soviet supply shock increased the quality-adjusted number of mathematicians in

39 In fact, the American Mathematical Society's 1991-1992 Academic Hiring Survey reported that the very high unemployment rate of new mathematics doctorates at the time was partly due to the fact that "citizens of Eastern European countries and the former Soviet Union accounted for 13\% of all newly-hired faculty" (McClure, 1992).

40 We replicated the analysis presented in this section using alternative definitions of the "first" field choice, including papers published in the first year, in the first five years, or in the first ten years, and the cohort trends are quite similar. 
the United States increased by 3.4 percent, while the respective increase in supply outside the United States was only 2.0 percent.

Figure 3 illustrates the trend in the cohort effects among mathematicians who first published between 1978 and 2009. The fraction of American and non-American dissertations in Soviet-style fields was relatively stable from 1978 through the late 1980s. In 1978, for example, 32.3 percent of American dissertations were in Soviet-style fields; by 1989, the respective fraction was 32.7 percent. Beginning around 1990, however, the relative number of Soviet-style dissertations produced by new American mathematicians began to decline, and this decline continued steadily through 2007. In 2007, for example, only about 22 percent of the dissertations produced by new American mathematicians were in Soviet-related fields.

To determine if the differential size of the supply shocks had a relatively larger effect on the dissertation field choices of students in the United States, Table 8 reports a regression analysis showing the magnitude of the cohort effects in the United States relative to those observed in the control group. The sample consists of all dissertations written by American mathematicians and by the control group. The dependent variable is an index of the "Soviet-ness" of a particular dissertation. It is evident that new entrants in the American mathematics market wrote many fewer Soviet-style dissertations after 1992 than mathematicians in the "rest of the world." In particular, the fraction of American dissertations published after 1992 in Soviet-style topics declined by 5.5 percent relative to those published abroad.

Finally, the last column of Table 8 examines an interesting aspect of the decline in the fraction of American dissertations written in Soviet-style topics. As we have seen 
repeatedly, the competitive effects induced by the Soviet influx tend to be attenuated for "high-ability" mathematicians. It would be of interest to determine if a person's innate productivity also influences the field choice made at the dissertation stage, and attenuates the cohort effects documented in this section.

We do not have any socioeconomic background variables that may hint at the person's overall quality at the time of the dissertation. However, a select group of American mathematicians (about 16.7 percent) entered the labor market with a "splash." In particular, they published more than one paper in their entry year. We define an indicator variable set to unity if the mathematician made a high-volume entry into the mathematics profession and estimate a regression model to determine if the cohort effects are similar among these prolific publishers. As the regressions show, the prolific American mathematicians were around 4.5 percent more likely to produce a Soviet-style dissertation prior to 1992, and this gap actually increased by an additional 2.3 percentage points after $1992 .{ }^{41}$ As with our earlier results, it seems that high-quality mathematicians are particularly prone to benefit from human capital spillovers, and these benefits influenced the choice of dissertation field for this select group after 1992.42

We conclude the empirical analysis by illustrating the relative impact—along all margins - of the Soviet supply shock on the composition of research topics pursued by the American mathematics community. In particular, Figure 4 illustrates the trends in the

\footnotetext{
41 The effect, however, is only marginally significant in the regression that uses the probability that the dissertation was in a Soviet-style field as a dependent variable. We also know which university awarded the mathematician's doctoral degree for about half of the American sample. We estimated some specifications that included a school-quality variable, but the results were not robust likely because of the sample selection.

42 Note that the initial field choice at the dissertation stage is not influenced by the mobility costs that must be incurred when moving from one location to another in the space of ideas.
} 
fraction of "active" mathematicians (i.e., mathematicians who published at least one paper during the specific year) who wrote a Soviet-style paper between 1971 and 2009.43 It is evident that there was little difference in the relative number of Soviet-style mathematicians in the United States and in the rest of the world prior to 1990, but the two communities diverged significantly after the differential supply shock resulting from the collapse of the Soviet Union affected the respective mathematical communities.

\section{Summary}

Economists have found that geographic mobility, occupational mobility, and job mobility are all important mechanisms that the labor market uses to adapt to supply and demand shocks. This paper introduces the notion of cognitive mobility as a key equilibrating mechanism in the market for knowledge production.

We examined empirically the labor supply shock that occurred in the space of mathematical ideas in the United States after the collapse of Soviet communism. Our analysis exploits the fact that the influx of Soviet mathematicians into the American mathematics community was clustered in a relatively small number of fields. The unbalanced nature of the supply shock across locations in idea space allows us to observe the flows of cognitive mobility unleashed by the changed economic opportunities resulting from the supply shock.

We constructed several empirical measures of cognitive mobility. Regardless of the measure, we document that the diminishing returns to specific research areas resulting from the increase in supply dominated the cognitive mobility decisions of pre-existing

\footnotetext{
43 The "active" mathematicians in the post-1992 period either in the United States or in the rest of the world do not include the Soviet émigrés.
} 
knowledge producers. This finding extends to new cohorts of mathematicians who entered the marketplace after the Soviet supply shock. The new cohorts increasingly chose dissertation topics that had experienced a relatively small increase in supply from the Soviet émigrés. In general, therefore, the evidence is clear: the Soviet supply shock led to cognitive mobility flows that drove American mathematicians away from those locations in idea space that received large numbers of Soviet émigrés.

Our analysis also begins to shed light into the black box of the cognitive mobility decision by delineating some of its determinants. We consistently observe that high-ability Soviet-style mathematicians were less likely to move to a different location in the space of ideas in response to the Soviet supply shock. This evidence suggests that high-ability mathematicians either have higher costs of movement or more positive net spillovers to interaction with other knowledge producers. Since high-ability mathematicians have shorter preparation spells and a smaller increase in the length of those spells due to the supply shock, the evidence is most consistent with the conjecture that high-ability mathematicians are the main beneficiaries of the positive spillovers.

Although our study addresses a central issue in the debate over the costs and benefits of high-skill immigration, it is difficult to infer straightforward policy implications from the evidence. Many of the potential gains from high-skill immigration likely arise because of the human capital externalities that high-skill immigrants can impart on the preexisting native-born workforce. Even though the vast majority of pre-existing American mathematicians did not benefit directly from the presence of their Soviet competitors, it may be the case that a small number of high-ability American mathematicians did. We do not yet know how to contrast the magnitude of the gains that accrued to a small number of 
American mathematicians with the losses suffered by the bulk of the pre-existing workforce. In fact, even those American mathematicians who "voted with their minds" and moved to non-Soviet research areas may have fertilized their new neighborhoods in ways that are not yet detectable or measurable. Further, even though the volume and direction of cognitive mobility flows may have been privately optimal, they may not have been the outcomes chosen by a social planner: knowledge producers ignore their own external effects when they make their cognitive mobility decision.

Finally, it is important to emphasize that our analysis focuses on the knowledge production function in a very specific marketplace: academia. There are a number of institutional constraints (e.g., tenure and relatively inelastic demand) that greatly constrain the nature of the potential gains from supply shocks in the academic marketplace. It is not hard to imagine that the same supply shock might have had very different productivity repercussions had it taken place in a competitive labor market.

In sum, although the study of the determinants and consequences of cognitive mobility is at its infancy, the evidence reported in this paper demonstrates that the flow of knowledge that an economy can produce depends intimately on the decisions of knowledge workers to change their location in the space of ideas. We suspect that further study of the process of cognitive mobility will lead to a greater understanding of knowledge spillovers, the knowledge production function, and the long-term impact of high-skill immigration on economic growth. 


\section{References}

Abramitzky, Ran and Isabelle Sin. 2000. Book translations as idea flows: The effects of the collapse of communism on the diffusion of knowledge. Unpublished manuscript, Stanford University.

Azoulay, Pierre, Joshua S. Graff Zivin, and Jialan Wang. 2010. Superstar extinction. Quarterly Journal of Economics 125, no. 2: 549-589.

Basu, Aparna. 2011.Mapping the network of mathematics using 'cognitive mobility' or migration of authors between fields as an index. In: Proceeding of ISSI $2011-$ The $13^{\text {th }}$ International Conference on Scientometrics and informetrics, ed. E. Noyons, P. Ngulube, and J. Leta.

Basu, Aparna and Roland Wagner Dobler. 2012. 'Cognitive mobility' or migration of authors between fields used in mapping a network of mathematics. Scientometrics 91: 353-368.

Borjas, George J., and Kirk B. Doran. 2012. The collapse of the Soviet Union and the productivity of American mathematicians. Quarterly Journal of Economics 127, no. 3: 11431203.

Borjas, George J., and Kirk B. Doran. 2013a. Cognitive mobility: Labor market responses to supply shocks in the space of ideas. NBER working paper no. 18614.

Borjas, George J., and Kirk B. Doran. 2013b. Which peers matter? The relative impacts of collaborators, colleagues, and competitors. Unpublished manuscript, Department of Economics, University of Notre Dame.

Cutler, David and Edward L. Glaeser. 1997. Are ghettos good or bad? Quarterly Journal of Economics 112, no. 3: 827-872.

Dubois, Pierre, Jean-Charles Rochet, and Jean-Marc Schlenker. 2012. Productivity and mobility in academic research: Evidence from mathematicians. Unpublished manuscript, Toulouse School of Economics.

Furman, Jeffrey, Margaret K. Kyle, Iain Cockburn, and Rebecca M. Henderson. 2005. Public \& private spillovers: Location and the productivity of pharmaceutical research. Annales d'économie et de statistique nos. 79-80: 167-190.

Galenson, David W. 2005. Old Masters and Young Geniuses: The Two Life Cycles of Artistic Creativity. Princeton, NJ: Princeton University Press.

Galenson, David W. and Bruce A. Weinberg. 2000. Age and the quality of work: The case of modern American painters. Journal of Political Economy 108, no. 4: 761-777. 
Ganguli, Ina. 2010. Saving Soviet science: The impact of grants when government R\&D funding disappears. Unpublished manuscript, Harvard University.

Ganguli, Ina. 2013. Immigration and ideas: What did Russian scientists 'bring' to the US? Unpublished manuscript, Stockholm School of Economics.

Grogger, Jeffrey, and Gordon H. Hanson. 2013. Attracting Talent: Location Choices of Foreign-Born PhDs in the US. Working Paper No. 18780, National Bureau of Economic Research, Cambridge, MA.

Hunt, Jennifer. 2012. The impact of immigration on the educational attainment of natives. Working Paper No. 18047, National Bureau of Economic Research, Cambridge, MA.

Hunt, Jennifer, and Marjolaine Gauthier-Loiselle. 2010. How much does immigration boost innovation? American Economic Journal: Macroeconomics 2, no. 2: 31-56.

Jones, Charles I., and Paul M. Romer. 2010. The new Kaldor facts: Ideas, institutions, population, and human capital. American Economic Journal: Macroeconomics 2, no. 1: 22445.

Kerr, William R.. and William F. Lincoln, 2010. The supply side of innovation: H-1B visa reforms and U.S. ethnic invention. Journal of Labor Economics 28, no. 3: 473-508.

Llull, Joan. 2010. Immigration, wages, and education: A labor market equilibrium structural model. Unpublished manuscript, Centro de Estudios Monetarios y Financieros (CEMFI).

McClure, Donald. 1992. AMS task force on employment report to the mathematical community_Part i: academic hiring survey, 1991-1992. AMS Notices 39: 754-758.

Moser, Petra, Alessandra Voena, and Fabian Waldinger. 2012. How much did the United States gain from the arrival of German-Jewish émigrés? Nazi expulsions and American scientific innovation. Unpublished manuscript, Stanford University.

Sjaastad, Larry. 1962. The costs and returns of human migration. Journal of Political Economy 70, no. 5, part 2: 80-93.

Wagner Dobler, Roland. 1999. Cognitive mobility: A macroscopic investigation of migration of scientists between research fields studied by the example of mathematics. In: Emerging Trends in Scientometrics, ed. P.S. Nagpaul, K. C. Garg, B.M. Gupta, S. Bhattacharya, A. Basu, P. Sharma, and S. Kumar. New Delhi: Allied Publishers.

Waldinger, Fabian. 2010. Quality matters: The expulsion of professors and the consequences for PhD student outcomes in Nazi Germany. Journal of Political Economy 118, no. 4: 787-831. 
Waldinger, Fabian. 2012. Peer effects in science: evidence from the dismissal of scientists in Nazi Germany. The Review of Economic Studies 79, no. 2: 838-861. 
Figure 1. Trends in cognitive mobility, 1978-2009

\section{A. Probability of publishing in a field different from dissertation}

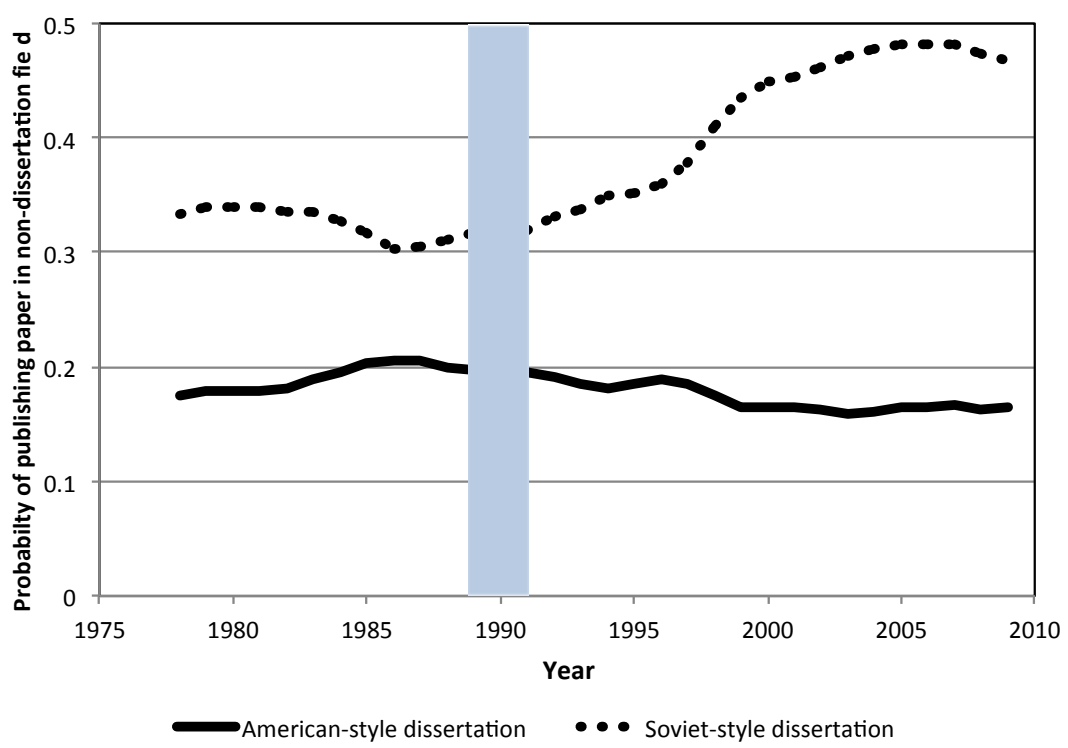

\section{B. Probability of publishing in a brand new field}

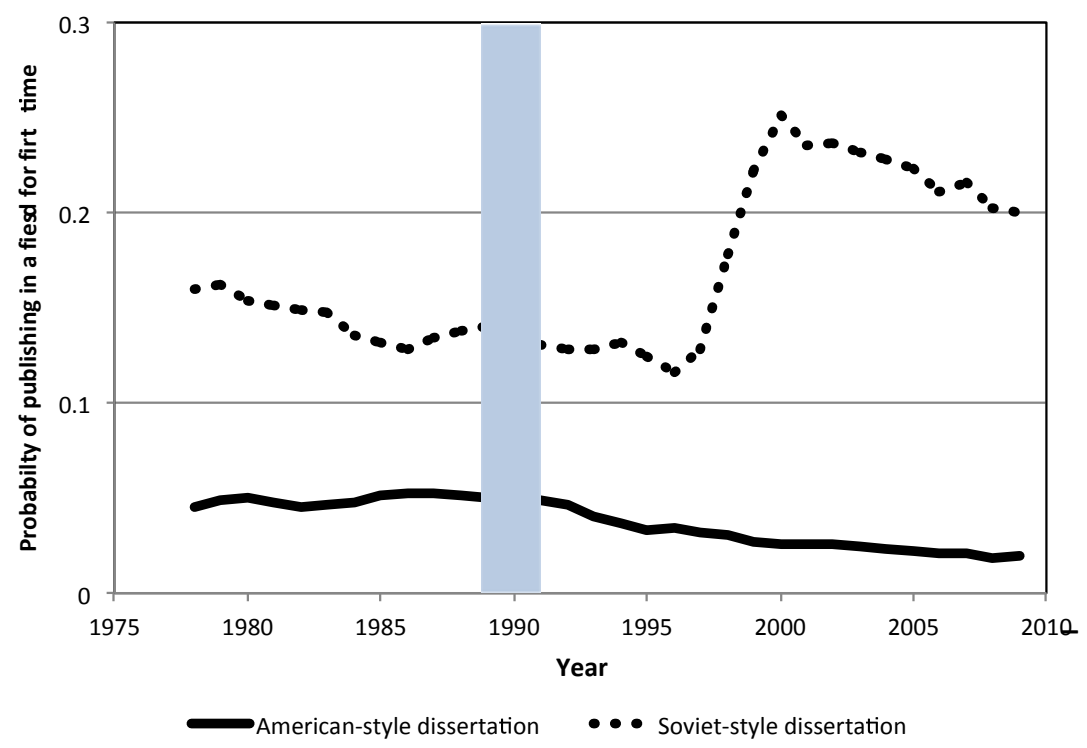

Notes: The sample consists of American mathematicians who first published before 1992. See Table 2 for the list of fields that are Soviet-style; all other fields, by definition, are American-style. We smooth out the trend by using a 3-year moving average of the rate of cognitive mobility centered on the middle year in the interval. The 'brand new field' variable in Panel B measures publishing for the first time in one of the two categories of fields (Soviet-style or American-style). 
Figure 2. Trends in cognitive distance from dissertation, 1978-2009

\section{A. Absolute value of cognitive distance (index of similarity)}

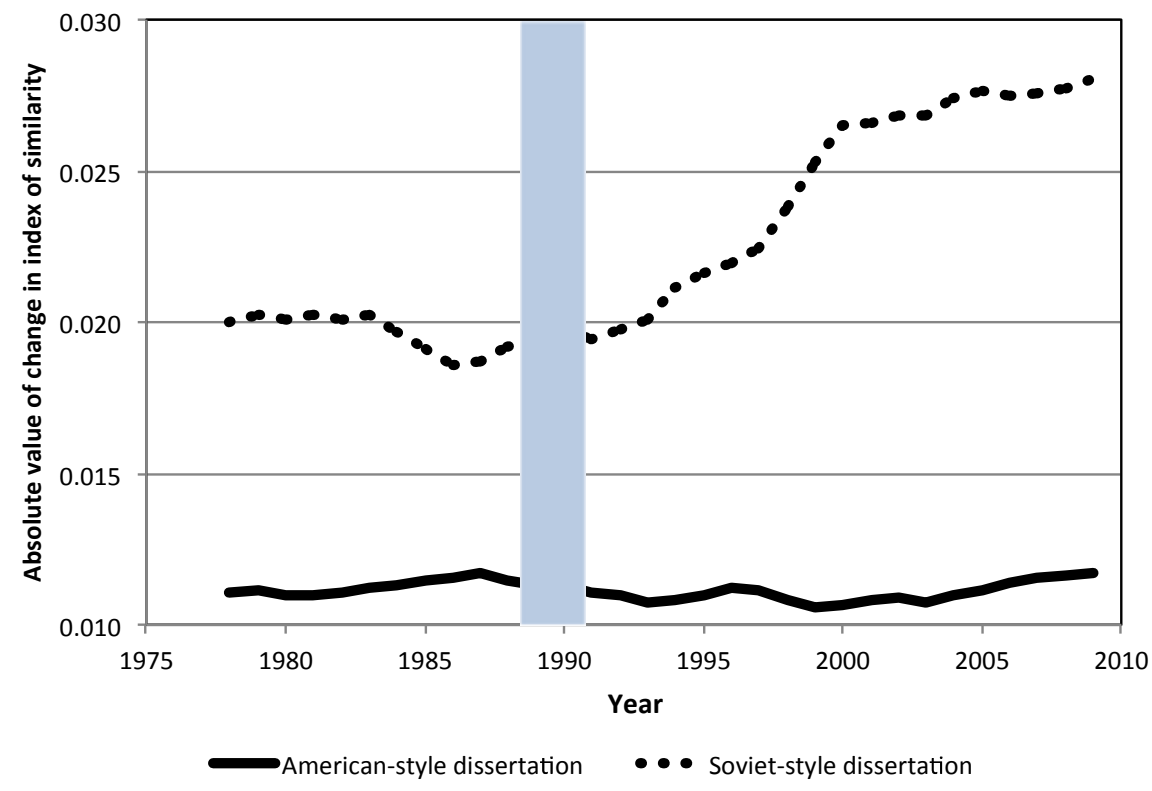

\section{B. Citation-based cognitive distance}

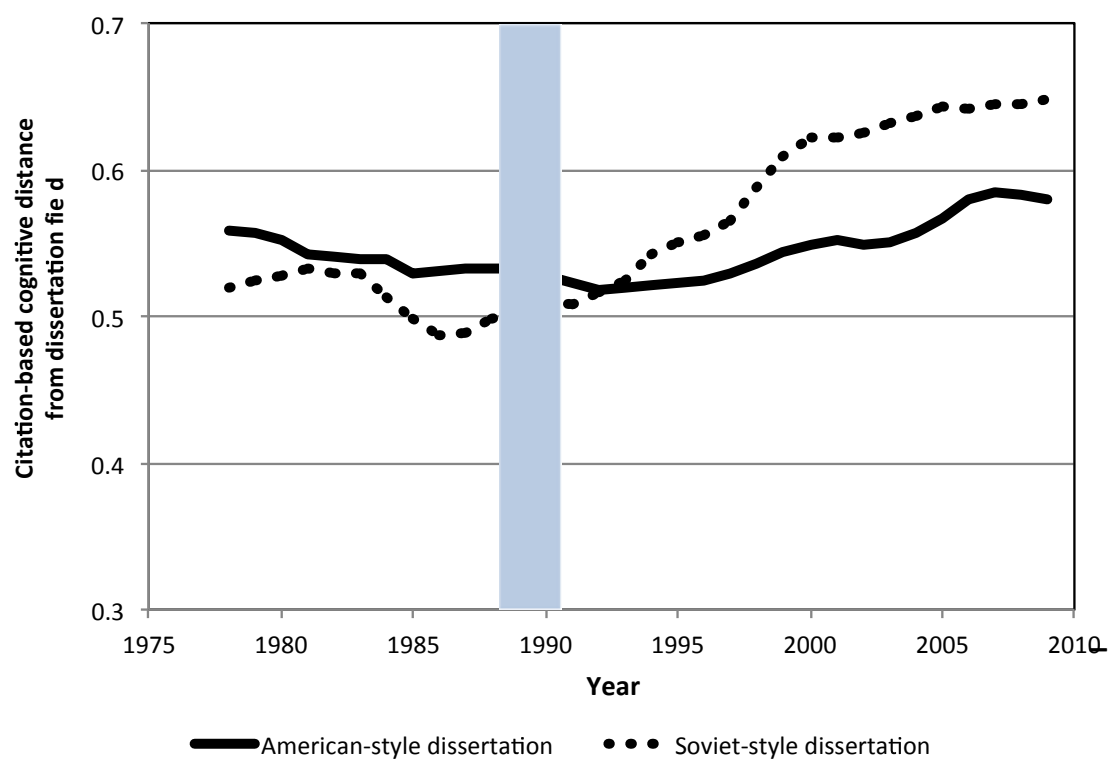

Notes: The sample consists of American mathematicians who first published before 1992. Cognitive distance in Panel A is defined as the difference between the average index of similarity for papers published in year $t$ and the dissertation's index of similarity, while in Panel B it is defined as the average citation distance between the papers published in year $t$ and the dissertation. We smooth out the trend by using a 3-year moving average of the measure of cognitive distance centered on the middle year in the interval. 
Figure 3. Trends in field of dissertation across cohorts, 1978-2009

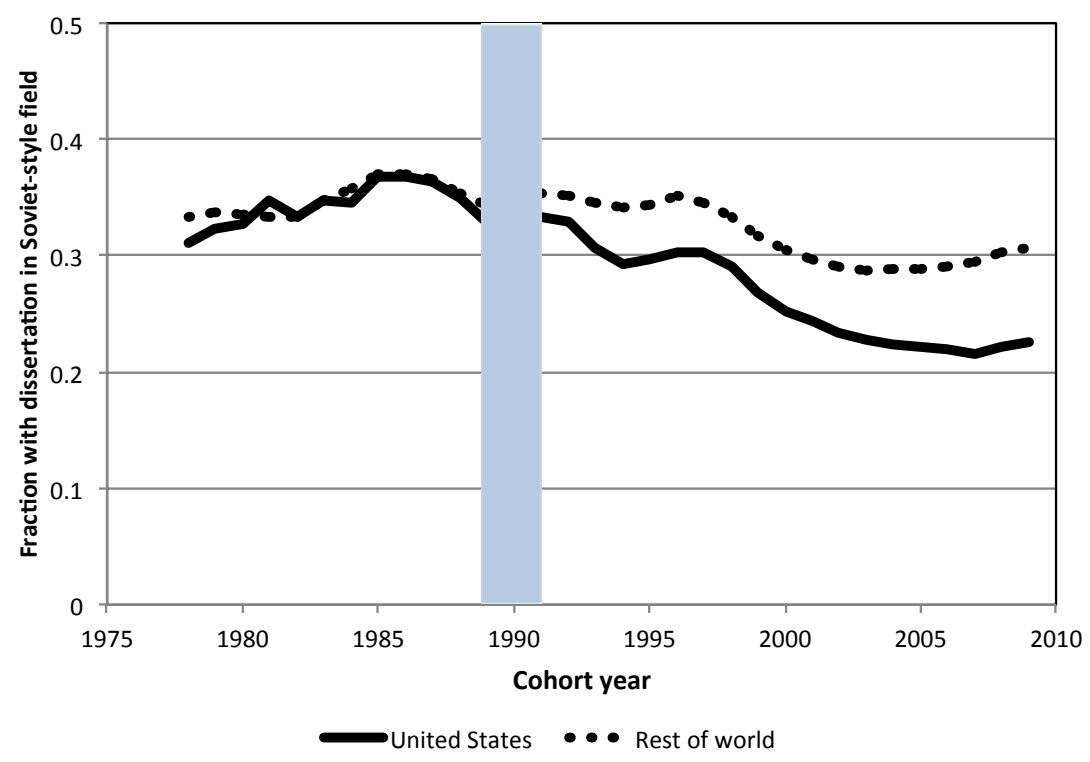

Notes: The sample consists of all mathematicians who first published between 1978 and 2009, and use the subject classification of the first published paper to measure the likelihood that the dissertation was in a Soviet-style field. We smooth out the trend by using a 3-year moving average centered on the middle year in the interval. The "rest of the world" does not include mathematicians in the Soviet Union (pre-1992) or in the territories encompassed by the former Soviet Union (after 1992). 
Figure 4. Aggregate trends in publications in Soviet-style fields, 1978-2009

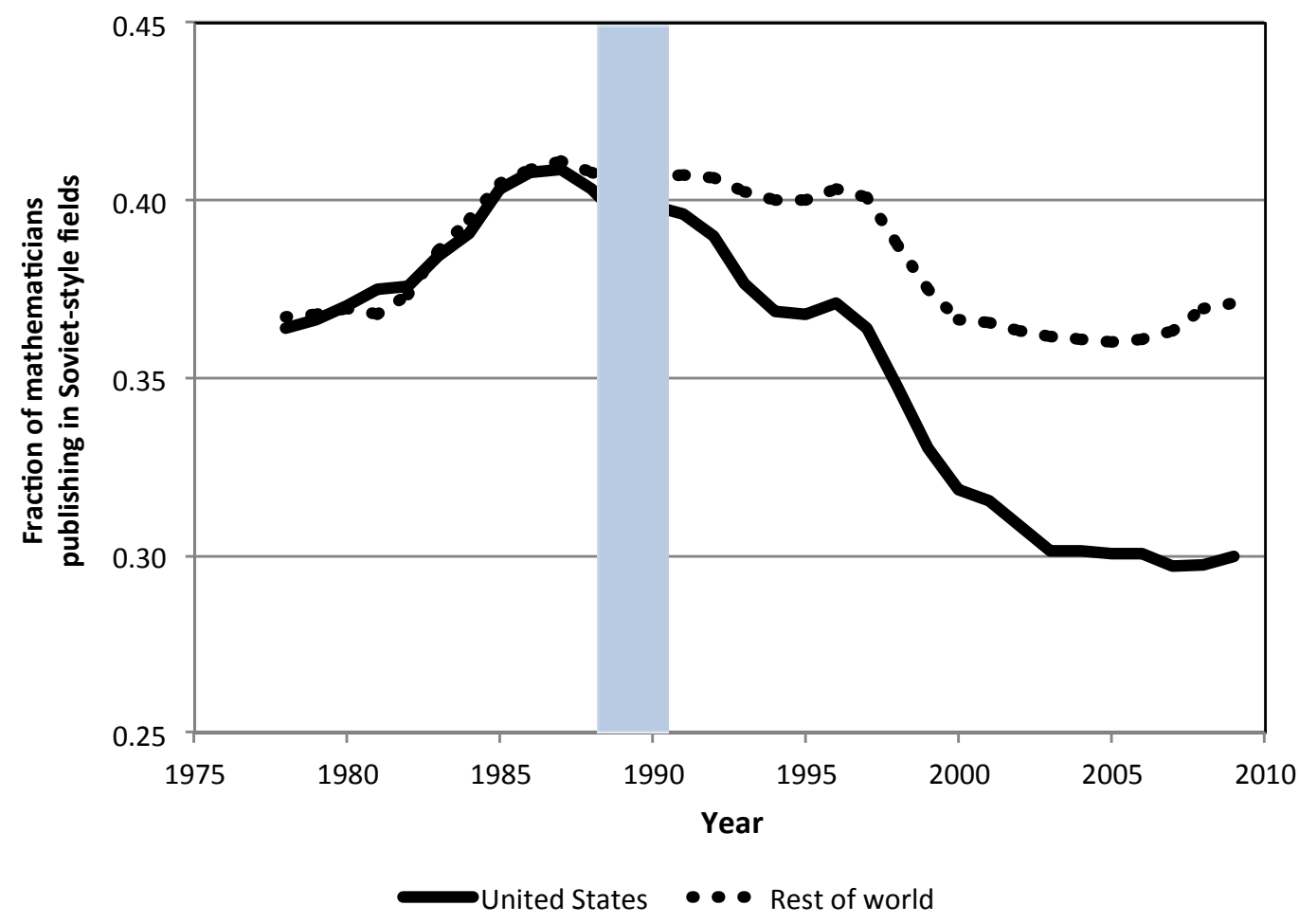

Notes: The sample consists of all mathematicians who published at least one paper during the year and excludes the sample of Soviet émigrés. The "rest of the world" does not include mathematicians in the Soviet Union (pre-1992) or in the territories encompassed by the former Soviet Union (after 1992). We smooth out the trend by using a 3-year moving average centered on the middle year in the interval. 
Table 1. Summary statistics, sample of American mathematicians

Variable:

Number of mathematicians

\begin{tabular}{ccc}
$\begin{array}{c}\text { All } \\
\text { mathematicians }\end{array}$ & $\begin{array}{c}\text { Pre-1992 } \\
\text { cohorts }\end{array}$ & $\begin{array}{c}\text { Post-1992 } \\
\text { cohorts }\end{array}$ \\
\hline 78,684 & 34,318 & 44,366
\end{tabular}

Number of papers:

Published 1940-2009

711,497

560,262

151,235

Published 1940-1991

330,370

Published 1992-2009

381,127

330,370

229,892

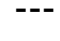

$-\cdot-$

Percent of papers in Soviet fields:

Published 1940-2009

.315

.326

.271

Published 1940-1991

.334

.334

.298

.316

$---$

Published 1992-2009

.281

.320

.251

Percent of dissertations in Soviet fields

Notes: The sample consists of all American mathematicians who first published between 1940 and 2009 . The "dissertation" paper is defined to be the first paper published by a mathematician. 
Table 2. Main fields of publications in the Soviet Union, 1984-1989

Field:

1. Partial differential equations

Share of papers Share of papers

published in the published in the

2. Ordinary differential equations

Soviet Union United States

3. Quantum theory

0.104

0.033

0.074

0.019

4. Probability theory and stochastic processes

0.068

0.059

5. Global analysis, analysis on manifolds

0.061

0.039

6. Operations research, mathematical programming

0.048

0.039

7. Numerical analysis

0.044

0.071

8. Operator theory

0.043

0.043

9. Statistical mechanics, structure of matter

0.031

0.019

10. Functions of a complex variable

0.029

0.026

0.028

0.015

Notes: The paper counts in each field are obtained directly from the web-based AMS Mathematical Reviews database (MathSciNet) and consist of all papers published by mathematicians affiliated with Soviet or American institutions between 1984 and 1989. 


\section{Table 3. Effect of the Soviet supply shock on the rate of cognitive mobility}

\begin{tabular}{|c|c|c|c|}
\hline \multirow{3}{*}{$\begin{array}{l}\text { A. Dependent variable = Paper in a field different } \\
\text { from the dissertation }\end{array}$} & \multicolumn{3}{|c|}{ Specification } \\
\hline & \multirow[t]{2}{*}{$(1)$} & \multirow[t]{2}{*}{$(2)$} & \multirow[t]{2}{*}{$(3)$} \\
\hline & & & \\
\hline Post-1992 indicator $\times$ Soviet-style dissertation & $\begin{array}{l}.123 \\
(.006)\end{array}$ & $\begin{array}{c}.125 \\
(.006)\end{array}$ & $\begin{array}{l}.140 \\
(.014)\end{array}$ \\
\hline Post-1992 indicator $\times$ Tenured as of 1992 & --- & $\begin{array}{c}-.002 \\
(.006)\end{array}$ & $\begin{array}{c}-.007 \\
(.006)\end{array}$ \\
\hline Post-1992 indicator $\times$ rate of output & --- & $\begin{array}{l}-.007 \\
(.003)\end{array}$ & $\begin{array}{l}-.003 \\
(.002)\end{array}$ \\
\hline $\begin{array}{l}\text { Post-1992 indicator } \times \text { Soviet-style dissertation } \times \\
\text { Tenured as of } 1992\end{array}$ & --- & & $\begin{array}{c}.009 \\
(.012)\end{array}$ \\
\hline Rate of output & --- & & $\begin{array}{l}-0.011 \\
(.006)\end{array}$ \\
\hline \multicolumn{4}{|l|}{ B. Dependent variable $=$ Paper in a brand new field } \\
\hline Post-1992 indicator $\times$ Soviet-style dissertation & $\begin{array}{l}.130 \\
(.007)\end{array}$ & $\begin{array}{l}.124 \\
(.007)\end{array}$ & $\begin{array}{l}.216 \\
(.015)\end{array}$ \\
\hline Post-1992 indicator $\times$ Tenured as of 1992 & -- & $\begin{array}{c}.001 \\
(.004)\end{array}$ & $\begin{array}{c}.003 \\
(.004)\end{array}$ \\
\hline Post-1992 indicator $\times$ rate of output & --- & $\begin{array}{l}-.015 \\
(.002)\end{array}$ & $\begin{array}{l}-.010 \\
(.001)\end{array}$ \\
\hline $\begin{array}{l}\text { Post-1992 indicator } \times \text { Soviet-style dissertation } \times \\
\text { Tenured as of } 1992\end{array}$ & --- & --- & $\begin{array}{l}-.035 \\
(.012)\end{array}$ \\
\hline Rate of output & --- & --- & $\begin{array}{l}-.062 \\
(.010)\end{array}$ \\
\hline
\end{tabular}

Notes: Standard errors are reported in parentheses and are clustered at the individual level. The sample consists of mathematicians whose first published paper was before 1992. All regressions include a vector of individual fixed effects, and a quartic control for years of experience. The "tenured as of 1992" variable indicates whether the mathematician had at least 10 years of experience as of 1992; the "rate of output" variable gives the annual number of papers published by the mathematician between the year of entry and 1991. The regressions in Panel A have 525,944 observations; the regressions in Panel B have 216,657 observations. The regressions in Panel B exclude all spells after the mathematician first switches to a field different from the dissertation. 


\section{Table 4. Sensitivity of regression results to alternative definitions of Soviet-style fields}

Dependent variable and definition of Soviet-style fields:

A. Paper in a field different from dissertation

1. Top ten soviet shares $\left(s_{f}\right)$

2. Top ten difference in shares $\left(s_{f}-a_{f}\right)$

3. Top ten relative shares $\left(s_{f} / a_{\mathrm{f}}\right)$

4. Top ten relative shares $\left(s_{f} / a_{f}\right)$ and $a_{f}$ is above median $\rho=$ post -1992 indicator $\times$ Soviet-style dissertation

\begin{tabular}{ccc}
\hline & $\rho \times$ Tenured & $\rho \times$ Rate of output \\
\hline & & \\
.140 & .009 & -.011 \\
$(.014)$ & $(.012)$ & $(.006)$ \\
.137 & -.013 & -.006 \\
$(.015)$ & $(.013)$ & $(.006)$ \\
.097 & -.020 & -.007 \\
$(.025)$ & $(.022)$ & $(.010)$ \\
.133 & -.005 & -.007 \\
& & \\
$(.014)$ & $(.013)$ & $(.006)$ \\
& & \\
.217 & -.035 & -.062 \\
$(.015)$ & $(.012)$ & $(.010)$ \\
.297 & -.089 & -.072 \\
$(.024)$ & $(.019)$ & $(.014)$ \\
.346 & -.077 & -.058 \\
$(.092)$ & $(.061)$ & $(.010)$ \\
.274 & -.080 & -.069 \\
& & \\
$(.022)$ & $(.016)$ & $(.013)$
\end{tabular}

$(.016)$
$(.013)$
B. Paper in a brand new field

1. Top ten soviet shares $\left(s_{f}\right)$

2. Top ten difference in shares $\left(s_{f}-a_{f}\right)$

3. Top ten relative shares $\left(s_{f} / a_{f}\right)$

4. Top ten relative shares $\left(s_{f} / a_{f}\right)$ and $a_{f}$ is above median

Notes: Standard errors are reported in parentheses and are clustered at the individual level. The sample consists of mathematicians whose first published paper was before 1992. All regressions include a vector of individual fixed effects, and a quartic control for years of experience. The "tenured as of 1992" variable indicates whether the mathematician had at least 10 years of experience as of 1992; the "rate of output" variable gives the annual number of papers published by the mathematician between the year of entry and 1991.The regressions in Panel A have 525,944 observations; the regressions in Panel B have 216,657 observations in row 1, 255,953 observations in row 2, 360,091 observations in row 3, and 256,737 observations in row 4; The regressions in Panel B exclude all spells after the mathematician first switches to a field different from the dissertation. 


\section{Table 5. The relative impact of the Soviet supply shock on American mathematicians}

\begin{tabular}{lcc} 
& \multicolumn{2}{c}{ Dependent variable } \\
\cline { 2 - 3 } & $\begin{array}{c}\text { Paper in a field } \\
\text { different from } \\
\text { the dissertation }\end{array}$ & $\begin{array}{c}\text { Paper in a } \\
\text { brand new } \\
\text { field }\end{array}$ \\
\cline { 2 - 3 } $\begin{array}{l}\text { Variable: } \\
\text { Post-1992 indicator } \times \text { Soviet-style dissertation }\end{array}$ & .094 & .110 \\
Post-1992 indicator $\times$ Soviet-style dissertation $\times$ & $.003)$ & .021 \\
American mathematician & .031 & $(.007)$
\end{tabular}

Notes: Standard errors are reported in parentheses and are clustered at the individual level. The sample consists of mathematicians whose first published paper was before 1992. All regressions include a vector of individual fixed effects, and a quartic control for years of experience. The regression in the first column has $1,909,179$ observations, and the regression in the second column has 869,849 observations. The regression that uses the "brand new field" dependent variable excludes all spells after the mathematician first switches to a field different from the dissertation. The regressions exclude the sample of pre-existing Soviet mathematicians (both émigré and non-émigré). 


\section{Table 6. Summary statistics on the duration of preparation spells}

A. Spell starts with:

American-style paper

Soviet-style paper

B. Spell involves transition to a new field and the dissertation

was:

American-style

Soviet-style

\begin{tabular}{cc}
\multicolumn{2}{c}{ Spell ends before } \\
1992 with: \\
\hline American- & Soviet-style \\
style paper & paper \\
\hline
\end{tabular}

.963

1.122

1.221

.756

Spell ends after 1992 with: American- Soviet-style style paper paper

Notes: A preparation spell is defined as the length of time elapsed between a mathematician's consecutive papers (in years). The sample consists of American mathematicians whose first published paper was before 1992. 


\section{Table 7. Effect of the Soviet supply shock on the duration of preparation spells}

Independent variable:

Soviet-style dissertation $\times$ New field at end of spell

Soviet-style dissertation $\times$ New field at end of spell $\times$ :

Post-1992 indicator

Soviet-style dissertation $\times$ New field at end of spell $\times$ post-1992

indicator $\mathrm{x}$ :

Tenured as of 1992

Rate of output

American-style dissertation $\times$ New field at end of spell

American-style dissertation $\times$ New field at end of spell $\times$ :

Post-1992 indicator

American-style dissertation $\times$ New field at end of spell $\times$ post-1992 indicator $\mathrm{x}$ :

Tenured as of 1992

Rate of output
Specification

\begin{tabular}{cc}
\hline$(1)$ & $(2)$ \\
\hline .790 & .194 \\
$(.054)$ & $(.086)$
\end{tabular}

1.340

(.162)

$(.285)$

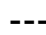

$---1.341$

(.227)

.738

.398

$(.045)$

.454

$(.104)$

Notes: Standard errors are reported in parentheses and are clustered at the individual level. The sample consists of mathematicians whose first published paper was before 1992. The regressions have 525,944 observations. The "new field at end of spell" variable is set to unity if the spell concluded with the mathematician publishing a paper in a field where he had never published before; the "tenured as of 1992" variable indicates whether the mathematician had at least 10 years of experience as of 1992; and the "rate of output" variable gives the annual number of papers published by the mathematician between the year of entry and 1991. All regressions include the mathematician's experience (defined as a fourth-order polynomial), a vector of individual fixed effects, and a vector of year fixed effects. The regressions also include all relevant smaller-order interactions between the tenured and rate of output variables and the dissertation style indicator, the new field indicator, and the post-1992 indicator. 


\section{Table 8. Effect of the Soviet supply shock on the dissertation field of successive cohorts of American mathematicians}

Variables:

A. Soviet-style dissertation

American mathematician

American mathematician $\times$ post-1992 indicator

Prolific mathematician

Prolific mathematician $\times$ post-1992 indicator

\begin{tabular}{cc}
\multicolumn{2}{c}{ Comparison group } \\
\cline { 1 - 1 } Rest of world & Americans only \\
\cline { 1 - 1 }-.006 & --- \\
$(.005)$ & --- \\
-.055 & \\
$(.006)$ & .045 \\
--- & $(.011)$ \\
-- & .023 \\
& $(.014)$
\end{tabular}

$-.010$

$-.027$

(.004)

$---$

$(.006)$

.017

(.007)

Notes: Standard errors reported in parentheses and are clustered by year of entry. The regressions use the sample of mathematicians whose first publication was between 1978 and 2009. The dependent variable in panel $A$ is a dummy variable indicating if the mathematician's dissertation was in a Soviet field, while the dependent variable in panel B is the similarity index associated with the mathematician's dissertation. The dummy variable indicating if the mathematician is "prolific" is set to unity if the mathematician published more than one paper in the year he entered the mathematics community. The regressions have 391,408 in column 1 and 64,290 observations in column 2. All regressions include a vector of year-of-entry fixed effects. 


\section{Appendix I. Creative Diversity Over the Life Cycle}

The empirical analysis demonstrates that American mathematicians who wrote a Soviet-style dissertation were much more likely to move to research activities on American-style topics after 1992. We now examine the evolution of a mathematician's research interests over the life cycle, and how the life cycle path of research interests was disrupted by the supply shock initiated by the collapse of the Soviet Union in 1992.

It is instructive to think of two distinct ways of summarizing how the cognitive mobility documented in Section III affects the life cycle path of research choices. At time $t$, for example, the field composition of a mathematician's publications in that particular year should reflect the impact of the various moves in idea space that have taken place up to that point in the life cycle. In addition, we can also define a cumulative measure of a mathematician's research interests by examining the field composition of all papers that he has published up to and including time $t$.

We estimate a regression model that allows us to quantify the impact of the Soviet supply shock on the aging-specialization profile. We aggregated the dataset constructed earlier to the author-year unit of analysis, so that an observation represents an author-year combination. By construction, an observation for a particular mathematician exists only in those years where the mathematician has published at least one paper. We first examine a measure summarizing the field mix of papers published by the author at time $t$. As noted above, the location of a mathematician in idea space at time $t$ is the end result of all the cognitive mobility decisions made by the mathematician prior to and including time $t$. We wish to determine how the field mix at a particular point in time changes over the cycle, and if this aging profile was displaced by the Soviet supply shock in 1992. Let $x_{i}$ denote mathematician $i$ 's years of experience, defined as the number of years elapsed between the time the mathematician first published and time $t$. We estimate the regression model given by:

$$
\begin{aligned}
\pi_{i t}=\delta_{\mathrm{i}} & +\delta_{\mathrm{t}}+\alpha_{1}\left(x_{i} \times S_{i}\right)+\alpha_{2}\left(x_{i} \times T_{i} \times S_{i}\right) \\
& +\beta_{1}\left(x_{i} \times A_{i}\right)+\beta_{2}\left(x_{i} \times T_{i} \times A_{i}\right)+\varepsilon,
\end{aligned}
$$

where $\pi_{i t}$ is the fraction of papers published by mathematician $i$ in calendar year $t$ that are Soviet-style. The coefficients of interest are contained in the vector $\left[\alpha_{1}, \alpha_{2}, \beta_{1}, \beta_{2}\right]$. This vector summarizes how the age-specialization profiles differ between Soviet- and American-style mathematicians, as well as before and after the Soviet supply shock. Note that the inclusion of individual and calendar year fixed effects implies that the differential impact of the shock on field choice is identified from variation within individuals (after controlling for whatever common "fads" may exist in field choice over time).

We estimate equation (A-1) by defining experience as a fourth-degree polynomial. The vector of coefficients of interest, therefore, is not easy to interpret (but the coefficients are reported in Appendix Table A-1). The results are much easier to understand by tracing out the age-specialization profiles implied by the estimated coefficients. Panel A of 
Appendix Figure A-1 illustrates how the age profiles differ among the four groups of interest. 44

It is evident that the different rates of cognitive mobility between American- and Soviet-style mathematicians before and after the Soviet supply shock create significant differences in their age-specialization profiles as well. The age profile of American-style mathematicians was roughly the same before and after 1992, although there is a tendency for the American-style mathematicians to publish slightly fewer Soviet papers at a given level of experience after 1992. However, the figure illustrates a dramatic difference in the age-specialization profile of Soviet-style mathematicians before and after the shock. In particular, the probability that a Soviet-style mathematician published a Soviet-style paper in the $20^{\text {th }}$ year of experience fell by about 10 percentage points after the shock.

In addition to the impact of prior cognitive mobility decisions on the field mix of papers published at time $t$, it is also interesting to examine the cumulative impact of the various moves in idea space on the field mix of a mathematician's entire life oeuvre. In particular, what fraction of all the papers that a mathematician has published by the time he has $x$ years of experience are in Soviet-style fields, and how was this cumulative summary measure affected by the Soviet supply shock?

We re-estimated the regression model in (A-1) using a dependent variable that gives the fraction of papers published by year $t$ that conduct Soviet-style research. 45 Panel B of Appendix Figure A-1 illustrates the age-specialization profiles implied by the estimated coefficients. Not surprisingly, the cumulative impact of the shock dampens the growth that would have otherwise occurred among American-style mathematicians in the fraction of a mathematician's cumulative work that dabbled in Soviet-style topics. In other words, for American-style mathematicians, the evidence suggests that the Soviet supply shock reduced the degree of creative diversity in their life oeuvre because it reduced incentives to engage in Soviet-style topics. In contrast, the figure shows a reduction in the fraction of cumulative papers that involve Soviet-style research for mathematicians who started out with a Sovietstyle dissertation. Put differently, the supply shock increased the degree of creative diversity that Soviet-style mathematicians experienced over their life cycle.

\footnotetext{
44 The predicted specialization rates are normalized to equal zero for all groups at the beginning of the life cycle.

45 This regression uses a "filled in" author-year dataset that contains an observation for each year of an active mathematician's life (regardless of whether he published or not) since we can observe the cumulative field distribution at any point in time. The panel includes all annual observations between the year of the mathematician's first publication and the $15^{\text {th }}$ year after the mathematician's last publication.
} 


\section{Appendix II. Data Construction}

The data used to construct our dependent and independent variables are drawn from a single database: the universe of publications in mathematics as archived by the American Mathematical Society (AMS) Mathematical Reviews. In order to define a sample of "American" mathematicians who were active in the American mathematical market before 1984, we also use data drawn from two additional databases: the Thomson Reuters' ISI Web of Science archive; and the Mathematical Genealogy Project (MGP) data that links new doctoral degrees granted in mathematics to their doctoral advisors.

\section{AMS Mathematical Reviews}

AMS Mathematical Reviews records the titles, publication sources, author names, references, fields, and citations of over 2 million articles from 2,764 different journals and publication sources worldwide. The editors of Mathematical Reviews also record subject classification codes for each paper in its database: 64 subfields defined according to the 2digit 2010 Mathematics Subject Classification (MSC2010), 104 subfields (3-digit MSC), or 610 subfields (5-digit MSC). We use the 2-digit coding throughout. Beginning in the early 1980s, the archival record of each published paper provides information not only on the author and the field of the paper, but also on the author's affiliation at the time the paper was published.

The AMS provided us with a spreadsheet containing the publication history of all mathematicians since 1939. A row in this spreadsheet defines a particular permutation of author $(i)$, field $(j)$, and year $(t)$. For each $(i, j, t)$ row we have information on: the number of papers published; the institutional affiliation(s) associated with the papers in that row; and the (country) location of the affiliation(s).

\section{Thomson Reuters' ISI Web of Science}

The ISI Web of Science records the titles, publication source, author names, references, and citations of millions of articles from thousands of journals worldwide. For many articles (especially after 1978), the database records research addresses and reprint addresses for each author. We purchased the records of all 1.2 million articles in the primary ISI Web of Science database between 1970 and 2009 for the following categories: Mathematics, Applied Mathematics, Interdisciplinary Applications of Mathematics, Mathematical Physics, and Statistics \& Probability. We also purchased the records of all 1.9 million articles referenced by these main articles, and the 2.4 million papers that cite these main articles. We obtained special permission from the AMS to merge our ISI papers by title, source, and author with the AMS database. The variables analyzed in this paper are not drawn from the matched sample. The ISI data are used to simply gather location information (between 1978 and 1984) for mathematicians who do not report any post1984 location in the AMS database.

\section{Mathematics Genealogy Project (MGP)}

For doctoral degrees awarded in mathematics, the MGP database reports the name of the degree recipient, the name of the doctoral advisor, the year in which the degree was completed, and the name of the institution granting the degree. In addition to these data, 
the MGP also provided us with each advisor's and student's AMS unique author identifier. The identifier allows us to merge MGP database with the AMS/ISI databases, and obtain all the available information on the publication and citation records of both students and advisors. The unique AMS identifiers are available for about 65 percent of degrees awarded since 1960.

\section{Construction of the sample of predominantly American mathematicians}

We focus on a sample of mathematicians whose first published paper occurred on or after 1940. The database provided to us by the AMS reports the mathematician's institutional affiliation and location for any year that the mathematician published at least one paper. In Borjas and Doran (2012), we used the AMS data to identify the number of times that the reported institutional affiliation prior to 1989 was located in the United States. We supplemented the information available in the AMS data by using both the ISI and the MGP data to define the sample of predominantly American mathematicians. As noted above, the ISI data contains affiliation and location information for many other published papers between 1978 and 1983. We use this location information if the equivalent post-1984 data are not available in the AMS. Finally, the MGP database reports the institution where the mathematician received the doctoral degree. A mathematician is then classified as "predominantly American" if the AMS/ISI location data indicate that more than half of the affiliations of publication prior to 1989 were located in the United States. If the pooled AMS/ISI data do not provide any information on the location of the mathematician prior to 1989, we assume that a mathematician who received a doctoral degree in the United States between 1950 and 1977 is affiliated with an American institution and he, too, is classified as predominantly American.

We employed this approach to define the sample of predominantly American mathematicians who first published after 1989. In particular, we examined the affiliation data in the AMS available for papers published in the first five years of the career, and classify a person as predominantly American if more than half of the papers published in that interval used an American affiliation. We used a similar approach to define the baseline sample of non-American mathematicians used in the cohort analysis reported in Section VII. 


\section{APPENDIX FIGURE A-1. The evolution of field specialization over the life cycle}

\section{A. Fraction of papers published in Soviet-style fields at time $t$}

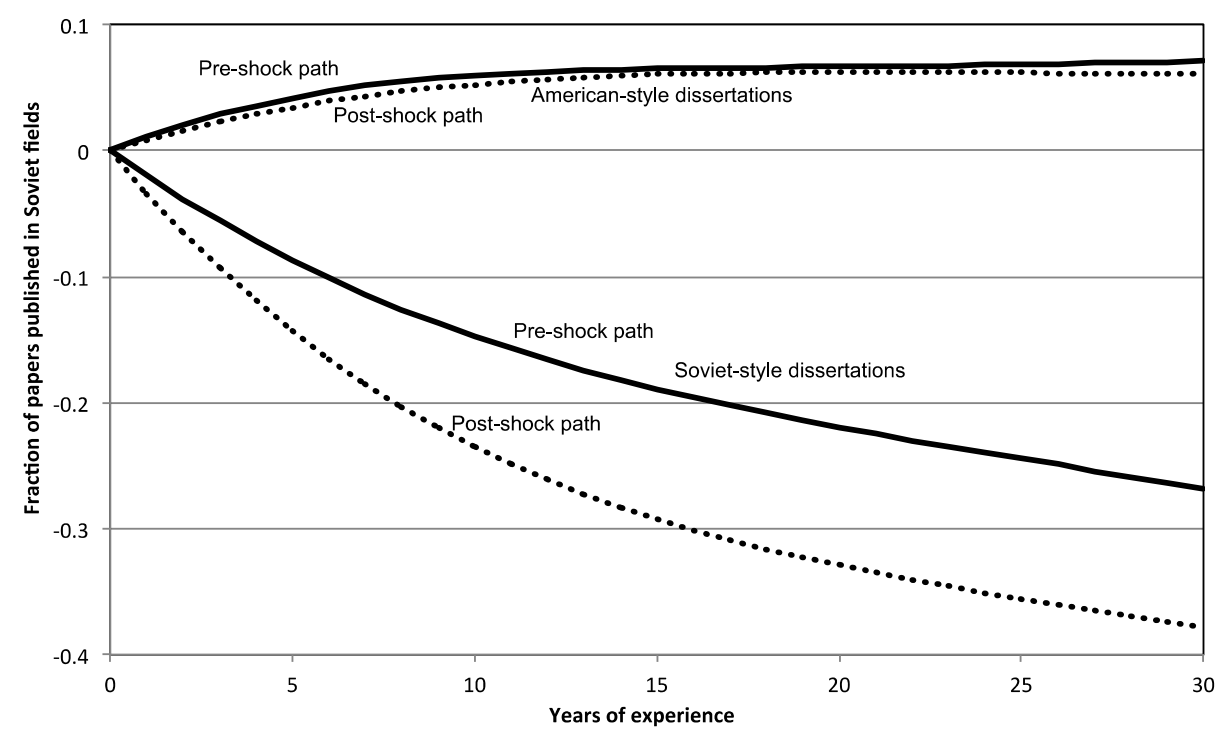

\section{B. Fraction of papers published in Soviet-style fields up to time $t \mid$}

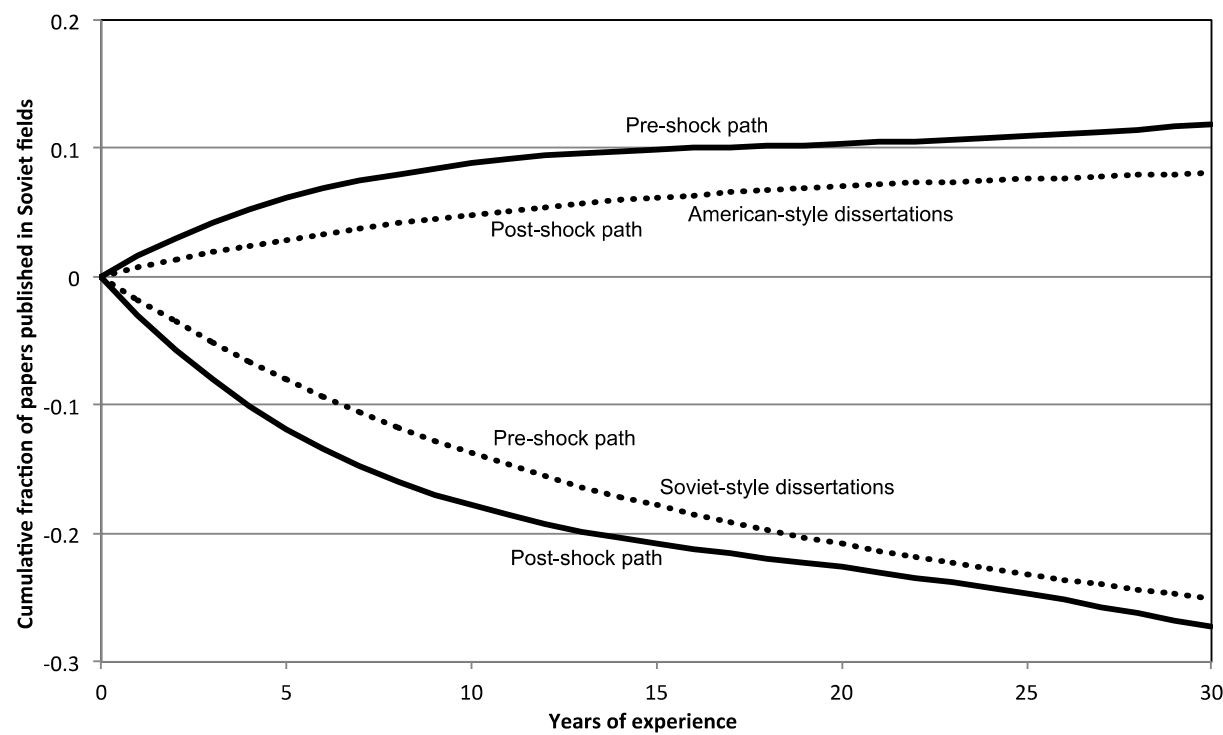

Notes: The sample consists of American mathematicians who first published before 1992. The agespecialization profiles are predicted using the regression model in equation (A-1); the estimated life cycle profiles are reported in Appendix Table A-1. See text for details. 


\section{APPENDIX TABLE A-1. Age-specialization profiles}

Dependent variable

\begin{tabular}{|c|c|c|}
\hline \multirow{2}{*}{$\begin{array}{l}\text { Independent } \\
\text { variable: } \\
A_{i} \times \text { : }\end{array}$} & $\begin{array}{l}\text { (1) Percent of papers published at time } t \text { that are } \\
\text { Soviet-style }\end{array}$ & $\begin{array}{l}\text { (2) Percent of papers up to time } t \text { that are } \\
\text { Soviet-style }\end{array}$ \\
\hline & & \\
\hline \multirow[t]{2}{*}{$T_{i}$} & -0.021 & -.010 \\
\hline & $(.006)$ & $(.001)$ \\
\hline \multirow[t]{2}{*}{ Experience } & .118 & .167 \\
\hline & $(.016)$ & $(.002)$ \\
\hline \multirow[t]{2}{*}{ Experience $^{2}$} & -.080 & -.106 \\
\hline & $(.016)$ & $(.002)$ \\
\hline \multirow[t]{2}{*}{ Experience $^{3}$} & .024 & .030 \\
\hline & $(.006)$ & $(.001)$ \\
\hline \multirow{2}{*}{ Experience ${ }^{4}$} & -.0026 & -.003 \\
\hline & $(.001)$ & $(.0001)$ \\
\hline \multicolumn{3}{|l|}{$A_{i} \times T_{i} \times:$} \\
\hline \multirow[t]{2}{*}{ Experience } & -.029 & -.098 \\
\hline & $(.030)$ & $(.005)$ \\
\hline \multirow[t]{2}{*}{ Experience 2} & .034 & .080 \\
\hline & $(.025)$ & $(.004)$ \\
\hline \multirow[t]{2}{*}{ Experience ${ }^{3}$} & -.014 & -.025 \\
\hline & $(.008)$ & $(.001)$ \\
\hline \multirow[t]{2}{*}{ Experience $^{4}$} & .002 & .003 \\
\hline & $(.001)$ & $(.0001)$ \\
\hline \multicolumn{3}{|l|}{$S_{i} \times:$} \\
\hline$T_{i}$ & -- & -- \\
\hline \multirow[t]{2}{*}{ Experience } & -.206 & -.319 \\
\hline & $(.023)$ & $(.004)$ \\
\hline \multirow[t]{2}{*}{ Experience 2} & .071 & .190 \\
\hline & $(.026)$ & $(.004)$ \\
\hline \multirow[t]{2}{*}{ Experience ${ }^{3}$} & -.013 & -.054 \\
\hline & $(.010)$ & $(.002)$ \\
\hline \multirow[t]{2}{*}{ Experience $^{4}$} & .001 & .006 \\
\hline & $(.001)$ & $(.0002)$ \\
\hline \multicolumn{3}{|l|}{$S_{i} \times T_{i} \times:$} \\
\hline \multirow[t]{2}{*}{ Experience } & -.146 & .131 \\
\hline & $(.042)$ & $(.006)$ \\
\hline \multirow[t]{2}{*}{ Experience 2} & .074 & -.128 \\
\hline & $(.038)$ & $(.006)$ \\
\hline \multirow{2}{*}{ Experience $^{3}$} & -.018 & .043 \\
\hline & $(.013)$ & $(.002)$ \\
\hline \multirow{2}{*}{ Experience ${ }^{4}$} & .002 & -.005 \\
\hline & $(.002)$ & $(.002)$ \\
\hline
\end{tabular}

Notes: Standard errors are reported in parentheses. "Years of experience" is defined as the number of years elapsed at time $t$ since the first publication, is divided by 10 , and is demeaned. The variable $S_{i}$ is set to unity if the mathematician's dissertation was in a Soviet field; $A_{i}=1-S_{i}$; and $T_{i}$ is a dummy variable indicating if the observation represents a year after 1992. The regressions have 199,251 observations (column 1) and 627,978 observations (column 2). All regressions include a vector of individual fixed effects and a vector of calendar year fixed effects. 